\title{
Un sistema de empleo público distópico: ¿sería preciso reformar el EBEP?
}

\section{A distopic public employment system: would it be necessary to reform the EBEP?}

Federico Castillo Blanco

Universidad de Granada (España)

ORCID: https://orcid.org/0000-0002-5586-0679

fblanco@ugr.es

\begin{abstract}
NOTA BIOGRÁFICA
Catedrático de Derecho Administrativo de la Universidad de Granada, en la actualidad es investigador principal del Proyecto I+D+i "Instrumentos para el buen gobierno de las cosas públicas: ética, transparencia e integridad pública", autor de distintas monografías, libros colectivos y artículos científicos sobre empleo público ha participado en distintos grupos de expertos sobre la misma materia incluida la Comisión EBEP.
\end{abstract}

\section{RESUMEN}

El presente trabajo analiza, atendiendo a la experiencia acumulada en los distintos ciclos de reforma del empleo público y las exigencias que actualmente tienen planteadas las Administraciones públicas, las distintas vertientes en que sería adecuado proceder a reformar el sistema de empleo público español explorando distintas soluciones a fin de enfrentar ese desafío que, como se concluye, no es meramente normativo e implica distintas acciones en la economía política de ese hipotético proceso.

\section{PALABRAS CLAVE}

Administración pública; empleo público; retos; objetivos; reforma; cambio cultural.

\begin{abstract}
The present work analyzes, taking into account the experience accumulated in the different cycles of public employment reform and the demands that public administrations currently have, the different aspects in which it would be appropriate to proceed to reform the Spanish public employment system, exploring different solutions to in order to face this challenge which, as it is concluded, is not merely normative and implies different actions in the political economy of this hypothetical process.
\end{abstract}

\section{KEYWORDS}

Public Administration; public employment; challenges; objectives; reform; cultural change.

\section{SUMARIO}

1. ¿ES PRECISO REFORMAR EL EBEP? 1.1. ¿HA FRACASADO EL CICLO DE REFORMAS QUE IMPULSÓ EL EBEP? 1.2. ¿POR QUÉ UNA REFORMA DEL EBEP NO PUEDE, POR SI SOLA, CAMBIAR LAS RÉMORAS QUE AQUEJAN AL EMPLEO PÚBLICO EN ESPAÑA? 1.3. ¿ES AHORA EL MOMENTO DE MODERNIZAR NUESTRO EMPLEO PÚBLICO? 2. LOS RETOS Y TENDENCIAS QUE MARCA- 
RÁN LA ADMINISTRACIÓN PÚBLICA Y EL EMPLEO PÚBLICO EN LA PRÓXIMA DÉCADA(S). 3. LOS CAMBIOS NECESARIOS EN EL SISTEMA DE EMPLEO PÚBLICO PARA AFRONTAR ESTOS RETOS. 3.1. LA ORGANIZACIÓN DEL EMPLEO PÚBLICO. 3.2. EL SISTEMA DE RECLUTAMIENTO Y SELECCIÓN. 3.3. SISTEMA DE RECOMPENSAS E INCENTIVOS. 3.4. EL SISTEMA DE INTEGRIDAD Y TRANSPARENCIA. 3.5. EL SISTEMA DE RELACIONES LABORALES. 3.6. LA PROFESIONALIZACIÓN DE LA GESTIÓN DEL EMPLEO PÚBLICO. 4. A MODO DE CONCLUSIÓN: CAMBIAR LA CULTURA PARA CAMBIAR EL SISTEMA. REFERENCIAS BIBLIOGRÁFICAS.

\section{1. ¿ES PRECISO REFORMAR EL EBEP?}

\section{1. ¿Ha fracasado el ciclo de reformas que impulsó el EBEP?}

La ventaja fundamental de nuestra burocracia pública, como oportunamente señaló Sánchez Morón (2012), es la profesionalización de nuestro régimen de empleo público que, a pesar de los pesares, se ha conseguido preservar en lo esencial desde hace prácticamente un siglo. Y ello, no obstante, indica dicho autor no haberse conseguido imponer el mérito sobre el criterio de la confianza política para el nombramiento de un número creciente de cargos de nivel superior y de ciertas disfunciones clientelares, más frecuentes en unas Administraciones que en otras. Todo hay que decirlo.

Estando conforme con dicha opinión, me temo sin embargo que, sólo con esa nota ciertamente imprescindible, no será suficiente para abordar los retos que el país enfrenta. Y es que no es menos cierto que existe un acuerdo mayoritariamente generalizado en la doctrina -igual podría decirse de los gestores de recursos humanos-, bien que por distintos motivos, de las carencias que el sistema presenta (Sánchez Morón, Jiménez Asensio, Gorriti, Fuentetaja, Cantero, Cuenca, Longo, Férez, etc.). Por resumirlo, y a juicio del primero de los autores citados, sigue siendo un sistema demasiado rígido, poco eficiente o productivo y en buena medida improvisado y desequilibrado.

Ciertamente, la observación de la realidad actual en el campo público refleja, con carácter general, un panorama necesitado de un replanteamiento y un nuevo impulso en lo que se refiere al empleo público. Y no exclusivamente en el plano normativo, sino más bien en el campo de la gestión y la profesionalización de éste. La gestión de los recursos humanos se realiza prácticamente en ausencia de establecimiento de objetivos o plan alguno, sin evaluación de los resultados, con una gran rigidez en las unidades orgánicas, en medio de la ausencia de una política de incentivos y sin una política salarial claramente definida, con un importante déficit en los mecanismos de racionalización y reasignación de efectivos en los que se ha operado -a salvo de momentos puntuales como ocurrió con la crisis económica- con una lógica incrementalista no necesariamente avalada por dato alguno, con una utilización de la formación en que sólo se tienen en cuenta los intereses de desarrollo personal de los miembros de la organización, etc. Prácticamente, y resulta un tanto desolador decirlo, en todos los campos de gestión de los recursos humanos del sector público hay amplios campos de mejora si se examina la cuestión con las «luces largas».

Y si lo hasta aquí expuesto no creo que pueda ponerse en cuestión por cualquier conocedor de ésta, también creo que puede ser unánimemente compartido que la función pública, el empleo público si queremos llamarlo así en la terminología EBEP, se enfrenta en los próximos años a innumerables desafíos derivados de distintos hechos. Entre otros, como se ha puesto de manifiesto por distintos autores (entre otros Jiménez Asensio, 2019a), las exigencias que impondrá el tránsito de una Administración analógica a otra predominantemente digital, a la previsible y masiva de pérdida de efectivos -conocimiento- que se dará en los próximos años como consecuencia de las numerosas jubilaciones (más de un millón según se anuncia), a la ingente deuda acumulada en estos últimos diez años que restringirá nuestra capacidad de respuesta a los desafíos, etc. que, junto a los retos y desafíos de los que más adelante daremos cuenta en este estudio, plantean de forma irremisible un necesario nuevo enfoque de las políticas que implementemos en este aspecto sin caer, de nuevo, en el mantenimiento de una institución que, en su planteamiento actual, está en gran medida agotada, un tanto inadaptada y carente del necesario impulso que la sociedad española requiere para acometer los cambios a los que se enfrenta.

Losada (2017) ha puesto de manifiesto que el reto a conseguir será, tanto la continuidad de los principios y límites que impone la Constitución, como un aumento significativo de la flexibilidad, una mayor tecnificación y especialización, progresar en la gestión de la heterogeneidad y una profundización en la «administración relacional» que constituyen los trazos clave que deberán informar la reforma del empleo público. Mas resumidamente, como puso acertadamente de manifiesto Longo (2004), combinar adecuadamente mérito y flexibilidad. 
Creo que es justo reconocer que el ciclo de reformas que el EBEP introdujo no son suficientes $\mathrm{o}$, al menos, no han dado los resultados esperados ${ }^{1}$. Dicho ello, ciertamente tampoco comparto la opinión de que se trató de una iniciativa frustrada o simplemente que se limitó a mantener el status quo existente. Ese marco normativo, con algunas modificaciones necesarias sin lugar a dudas, bastaría para dar respuesta a las principales exigencias que el momento actual, y seguramente, las próximas décadas plantean al menos en la mayoría de los aspectos que se apuntarán. A título de ejemplo, entre otros aspectos, no creo que pueda culparse a la norma de la extensión deliberada del régimen funcionarial sin causa que lo justifique suficientemente, que sigan sin racionalizarse y flexibilizarse las estructuras organizativas, a planificarse una adecuada previsión de incorporación de efectivos, que mejoremos nuestros sistemas de selección y reclutamiento, que no se haya desplegado una política de incentivos o no se haya procedido, una vez por todas, a la implementación de una dirección pública profesional. Creo sinceramente que la respuesta no puede ser otra que no.

Entonces ¿Qué ha acontecido para que el resultado no sea satisfactorio?. En mi opinión es algo más sencillo de explicar, y seguramente más difícil de resolver. Creo que, entre otras que también podrían apuntarse, dos son las razones que explican que las dinámicas e inercias en las que se mueve nuestro empleo público en las últimas décadas se hayan terminado imponiendo. Ambas tienen que ver más con la economía política de un proceso de reformas como el que planteaba el EBEP (no suficientemente atendida) y el propio marco institucional en que éste había de desenvolverse ${ }^{2}$, que con el propio texto y las propuestas que éste formulaba.

La primera es que el modelo implementado por el EBEP exigía, en nuestro marco constitucional como más adelante se expondrá, ser completado con la labor del legislador ordinario de desarrollo (Estado, CC.AA y negociación colectiva) y esa tarea no era un tema menor. El EBEP es un texto directivo, pero también dispositivo y diferido en su implementación efectiva que requería del esfuerzo y colaboración de otros niveles de gobierno. Las reformas dependen del sistema de gobernanza pública por decirlo de una vez. Y es ahí donde, tanto por factores exógenos que facilitaron la pérdida de impulso de la norma (la crisis económica de 2008 principalmente), como por factores endógenos ligados principalmente a las resistencias de los actores llamados plasmar en políticas concretas la función directiva y modernizadora que la norma contenía, se ha perdido la ventana de oportunidades y políticas en la buena dirección que la norma establecía. Nos guste o no el marco institucional del empleo público es ese. Sin grandes consensos políticos (y sindicales hemos de añadir), dada la fragmentación del sistema, será tremendamente complejo avanzar en este laberinto. Mírese, si hay alguna duda, cómo la mayoría de las propuestas que se realizan de mejora de la gestión de recursos humanos en nuestro sector público no son ni opuestas y mucho menos imposibles de implementar en el marco del EBEP. ¿Por qué no se realizan?

La labor del legislador ordinario y la labor de la jurisprudencia en ciertos aspectos tampoco ha sido de gran ayuda, bien es cierto la limitada función de esta última si exceptuamos la referida a los necesarios frenos frente a la arbitrariedad. En lo que se refiere al legislador ordinario, allí donde se ha producido (la AGE, a título de ejemplo, no lo ha realizado renunciado con ello a la necesaria labor directiva y de impulso reformador que le debiera haber correspondido), lamentablemente se ha optado, en la mayoría de sus aspectos, por mantener en lo esencial, con leves modificaciones y desde luego sin incidir en forma suficiente en los problemas apuntados, el modelo de empleo público que ya teníamos y que se revela a estas alturas exiguo para atender los retos que se ciernen sobre nuestro país.

La segunda razón tiene que ver con la capacidad de gestión de nuestras Administraciones públicas en lo que a esta materia se refiere que hace ciertamente complejo implementar una profesionalización de la gestión -en algunos casos como la esfera local dada la planta de ésta es cercano a lo imposible (Jiménez Asensio, 2019b)- que consiga los objetivos deseados por las normas y no reducir la función de gestión de recursos humanos en el sector público meramente a administrar expedientes de gestión de personal (la nó-

En opinión de SÁNCHEZ MORÓN (2012) en la obra citada, «el último intento general de abordarlos, que se puso en marcha con la preparación del EBEP, ha sido en gran medida y a la postre un intento fallido, pues muchas de las propuestas que se formularon por la Comisión creada al efecto no llegaron al texto de la Ley o bien se recogieron en ella de manera ambigua o descafeinada, como meras posibilidades a concretar por una legislación de desarrollo que hasta ahora no ha visto la luz de forma generalizada. Frente al impulso reformista prevaleció una lógica conservadora del modelo existente y los intereses propios de los partidos y de los sindicatos más representativos». Y, añadamos nosotros, que cuando se han plasmado en la legislación de desarrollo se ha preservado, en gran medida, el modelo actual con puntuales cambios, más estéticos que efectivos en la práctica, que a la postre siguen sin abordar los principales problemas que en esta materia se han reiteradamente detectado y apuntado por múltiples especialistas.

2 A estos efectos es de ineludible consulta el trabajo de VELASCO CABALLERO (2019) que pone de relieve las dificultades intrínsecas a nuestro sistema, tanto político como jurídico, para afrontar reformas de gran calado. 
mina, los permisos, las excedencias, etc.). La experiencia pone de relieve que subsistemas de gestión de recursos humanos que podrían haber sido operados con éxito, como entre otros el sistema salarial, finalmente han terminado siendo adulterados perdiendo el carácter motivador que éste puede representar.

Por tanto, y ya conviene dar respuesta a la pregunta que se ha planteado en este epígrafe en torno a si puede considerarse el EBEP una norma fracasada, creo que debe contestarse más bien con el aserto de qué el EBEP ha sido, en verdad, una norma huérfana. Del legislador ordinario, de la jurisprudencia, de los actores llamados a implementar la reforma, etc. lo que ha sido determinante para que la misma no haya alcanzado los objetivos que se pretendieron al dictarse. Aunque bien es cierto que su promulgación ha conseguido, y no es poco, instalar en el debate público algunos de los cambios necesarios en la gestión del empleo público y ser recogidos normativamente. Sin embargo, y no debe olvidarse, los cambios en las normas no consiguen cambiar los comportamientos ni la cultura que los guía y dictada una nueva norma sino cambiamos estos extremos se seguirán produciendo similares resultados.

No quiero, sin embargo, restar capacidad a las normas para resolver muchas de las lagunas que se dan en este ámbito, pero si poner de relieve simplemente, como ya se ha hecho notar, que la mera existencia de las mismas no cambiará por si solas muchos de los defectos que se vienen señalando. Y nuevas normas, sin una lectura adecuada de por qué no se obtuvieron los resultados deseados con las normas que se desechan, me temo que nos condenará de nuevo a lamentarnos pasado un tiempo del fracaso de las mismas como han puesto de relieve algunos estudios como los realizados por la OCDE (2006) evaluando los ciclos de reformas en el sector público y que ponen de relieve, tanto que los cambios hechos en las reglas, estructuras y procesos no consiguen por si solos cambiar los comportamientos y las culturas, cómo que las reformas sólo serán efectivas cuando consiguen inducir el cambio en una diversidad de actores. Y es que quizás lo más relevante son las lecciones aprendidas. En efecto, cuando se habla de reformas del sector público, en opinión de la OCDE en el citado Informe, si bien éstas han conseguido que los gobiernos en general sean hoy más eficientes, transparentes, receptivos y focalizados en el desempeño que con anterioridad, no cabe olvidar distintos aspectos qué, como la complejidad del sistema de gobernanza pública en que éstas se insertan, concebir las reformas como un proceso continuo y el necesario cambio cultural que implican exigen consideraciones adicionales. Amén de ser conscientes de que una reforma integral del empleo público no puede desgajarse de una más amplia que afecte a la organización, procedimientos y formas de actuación del conjunto de nuestras Administraciones públicas.

A buen entendedor pocas palabras basta dice un refrán castizo en nuestro país. Quizás si se considerase estas cuestiones tendríamos un mayor éxito en las reformas que del sector público, y del empleo público como elemento inescindible de éste, se abordasen.

\section{2. ¿Por qué una reforma del EBEP no puede, por si sola, cambiar las rémoras que aquejan al empleo público en España?}

La aprobación del Estatuto Básico del Empleado Público supuso, en nuestro sistema constitucional de relación bases-desarrollo, una nueva propuesta legislativa que creo ha llegado para quedarse en buena medida dado nuestro sistema de cogobernanza pública como ahora gusta, no sin cierta imprecisión, denominarlo. En efecto, como es suficientemente conocido, las propuestas formuladas partían de elaborar un Estatuto Básico de menor extensión, que contuviese normas de aplicación directa, pero con una eminente función directiva, susceptible de ser adaptado por la legislación de desarrollo a las características propias de cada Administración, de acuerdo con las opciones de los órganos parlamentarios y de gobierno competentes; un Estatuto, como se indicaba en el Informe que precedió a éste realizadas de forma previa por una Comisión constituida al efecto, «que contenga solamente aquello que convenga regular para el conjunto de las Administraciones Públicas».

En el sentir de la Comisión aludida el Estatuto debería constituir una norma básica que permitiese a todas y a cada una de las Administraciones, sobre la base de un sustrato común de derechos y deberes de los empleados públicos, acometer las reformas específicas que requiriese la modernización de su sistema de empleo público permitiendo adaptar su modelo de empleo público a los requerimientos y las finalidades de su propia organización. Las propuestas de la Comisión, por tanto y en esta línea, acogían distintas posiciones de lo que debía ser entendido como básico, verbigracia: en unos supuestos, el Estatuto debería contener normas de obligado cumplimiento; pero en otros casos dichas normas no tendrían sino un carácter habilitador o de directriz. Inclusive el texto final, y según lo ya expuesto, acogió otras funciones de lo denominado básico, ciertamente más discutibles, como norma o menú dispositivo o de configuración de un estándar 
mínimo o supletorio en otros supuestos. Lamentablemente, y creo que esto si debiera de ser una lección aprendida, los principales vectores de impulso de una nueva gestión de los recursos humanos en el sector público solo tuvieron, en la mayoría de los casos, un carácter meramente orientativo.

El resultado inmediato de esta propuesta legislativa se tradujo en separar netamente la función constitucional específica de ordenación competencial atribuida al Estado a través de la legislación básica, de la función de regulación ordinaria en el ejercicio de sus competencias que no puede ni debe confundirse con la anterior si bien no era esto lo que había ocurrido hasta ese momento (Balaguer Callejón, 2006). Se produjo, con ello y a efectos prácticos de lo que en este punto interesa subrayar, un efecto indirecto en el legislador estatal de contención a la hora de establecer las bases del sistema de empleo público que sólo y exclusivamente se refirió a aquellos aspectos que consideraba estructurales del sistema de empleo público de todas las Administraciones públicas remitiendo a leyes del Estado y de las Comunidades Autónomas el desarrollo de dichas previsiones a fin de que completasen el modelo de empleo público que, por definición constitucional, es un modelo que ha de ser definido en su integridad con la colaboración de estas Administraciones. De otro lado, y por esa misma razón, hacía descansar la responsabilidad de la mejora del modelo respecto de su propio empleo público en la AGE, las Comunidades Autónomas y los entes locales cuya colaboración era imprescindible para que las lógicas impulsadas por la reforma alcanzasen el éxito que se pretendía.

Por tanto, tras su aprobación, correspondía fundamentalmente a la AGE y a las Comunidades Autónomas continuar la senda emprendida en esta reforma que, sin duda, se emprendió tras una cierta demora ${ }^{3}$. Desgraciadamente los hechos acontecidos en estos últimos años -primero la crisis económica y ahora la derivada de la pandemia- han ralentizado las reformas emprendidas allí donde se habían iniciado, han demorado las mismas en aquellas CC.AA que no las habían emprendido y, en fin, también ha acentuado algunas disfunciones del sistema muy específicamente en el sector local donde la normativa de la crisis (la LRSAL) introdujo más confusión que soluciones a los problemas que ya estaban planteados.

En cualquier caso, del planteamiento efectuado cabe desprender una primera conclusión. No basta, ni mucho menos, una reforma del EBEP para abordar la necesaria reforma del empleo público. Si duda será esencial, pero se ha de ser consciente de que el modelo constitucional de empleo público no se construye en exclusiva por el Estado. Y en ese intento realizado a partir de 2007 no se ha tenido el éxito esperado. Inclusive algún autor como Jiménez Asensio se ha preguntado, y con razón hemos de añadir, si en verdad podemos decir que existe una institución como la función pública en nuestro país o «no existen más que una diáspora desordenada de funcionarios o empleados públicos que dependen de una u otra administración pública, cuya única nota común es una cada vez más vaga e inadaptada legislación básica, así como un isomorfismo institucional propio de la pereza de los legisladores o de la resistencia al cambio de la propia burocracia (siempre cómoda en su zona de confort) reforzada por la defensa numantina de prerrogativas de los empleados públicos por un sindicalismo con mirada estrecha, cuando no corporativa» ${ }^{4}$. Existe, ciertamente, un riesgo de fragmentación del sistema como consecuencia de la descentralización realizada, más bien de las patologías asociadas a ésta, que no debe ser obviada y que requiere la articulación de técnicas que reconduzcan a una cierta homogeneidad el modelo a fin de poner un freno efectivo a ese proceso.

3 Esta demora, inexplicable ciertamente, puede encontrar explicación, a juicio de JIMÉNEZ ASENSIO y CASTILLO BLANCO (2009: 104), en dos factores: «El primero, como se ha visto, es que el EBEP es una norma compleja que hasta cierto punto supone un cambio de paradigma en el modo y manera de configurar el empleo público. Requiere un cambio de cultura de la organización, una inversión en nuevos instrumentos y herramientas de gestión, así como una potenciación y refuerzo institucional de las unidades de gestión de recursos humanos en las Administraciones Públicas. En suma, un cúmulo de retos, pero que abren asimismo no pocas oportunidades para una mejora y modernización de las vetustas estructuras y métodos de gestión de personas en nuestras organizaciones públicas. El segundo factor, mucho más contingente (al menos eso esperamos), es la crisis económica que azota a las economías occidentales (aunque se puede afirmar que es una crisis globalizada) y, especialmente, a España. El EBEP es, y así se debe reconocer, una norma "cara" en su aplicación, sobre todo depende como se haga esta. Dicho rápidamente, poner en marcha un buen sistema de evaluación del desempeño, así como luego aplicarlo de forma óptima, requiere un gasto notable. Lo mismo se puede decir de la implantación de un sistema de carrera profesional horizontal, pues si no se hace de forma escalonada y racional el incremento de gasto puede generar puntas insostenibles que presionen sobre unos depauperados presupuestos. En menor medida, una buena dirección pública profesional requiere de alguna necesaria inversión, así como la puesta en marcha de una potente unidad de recursos humanos exige gasto».

4 Puede verse, en este sentido, las atinadas reflexiones del autor en "Una función pública para transformar España" en $h t t p s: / /$ rafaeljimenezasensio.com/2020/09/27/una-funcion-publica-para-transformar-espana-i/ quien reflexiona "que la institución de función pública ofrece una realidad muy variopinta y escasamente compacta como consecuencia de su acantonamiento estructural en los niveles de gobierno, que disponen de subsistemas de personal cerrados entre sí, sin vasos comunicantes ni pasarelas o tránsitos horizontales ni tampoco verticales entre los profesionales que los conforman. En un universo hermético como es el descrito, la endogamia y la visión estrecha de sus propios problemas domina e hipoteca, cuando no empobrece, la función pública española del siglo XXI». 
Pero eso no es todo. Si alguna lección aprendida puede sacarse del ciclo de reformas iniciado con el EBEP sin duda alguna es la incapacidad del marco normativo impulsado como se ha hecho hasta ahora, por sí solo, para transformar el empleo público. Se exige, más allá de ello, un gran acuerdo político, sindical e institucional ya que las reformas normativas que se emprendan han de contar con la complicidad del legislador autonómico pues no se olvide que el grueso de nuestro empleo público se encuentra en el ámbito autonómico y en el local y es a éste legislador, y a la negociación colectiva en lo que se refiere al ámbito laboral, al que compete tomar decisiones más concretas que plasmen en la práctica los principios que inspiren una eventual reforma. En caso contrario me temo que cualquier intento se verá capitidisminuido y anulado finalmente, como hasta ahora ha sucedido en los intentos de reforma acontecidos desde la década de los sesenta del pasado siglo, por los indisimulados «intereses» existentes en este ámbito.

\section{3. ¿Es ahora el momento de modernizar nuestro empleo público?}

Cualquier observador informado contestaría afirmativamente a la pregunta planteada. Aún más, seguramente añadiría que llegamos tarde. El empleo público en España constituye un importante colectivo. Más de dos millones y medio. Un funcionamiento adecuado de éste, por tanto, y a la vista de tales cifras, no resulta una cuestión menor para el conjunto de nuestras Administraciones públicas. La idoneidad y eficacia de los servicios que se prestan a los ciudadanos van a depender, en gran medida, de su adecuada estructuración, profesionalización y motivación.

Y es que ahora, con pandemia o sin ella, es necesario retomar la senda de reformas. La construcción de la burocracia profesional que nuestro país demanda así lo exige. Y también, por ello, es un buen momento para tener en cuenta nuevos elementos en relación a la prestación de los servicios que estos años nos han puesto de relieve, entre otros a los que se hará referencia, a la prestación de servicios mediante el denominado "teletrabajo», las cuestiones atinentes a la integridad pública o, por apuntar una última cuestión, la rigidez todavía existente en la movilidad y funciones a desarrollar por los empleados públicos. Por demás, los grandes motores de cambio que introdujo el EBEP siguen en gran medida adormecidos, a saber: a) La carrera profesional (sobre todo la implantación de la carrera horizontal); b) La evaluación del desempeño; y c) La figura del directivo público profesional. Pero a éstos creo que conviene añadir algunos otros que parecen, a día de hoy, ineludibles.

Si efectivamente, y como se reconoce con carácter general, nuestro país ha sufrido importantes cambios en las últimas cuatro décadas, dichas transformaciones no se han traducido suficientemente en las formas de operar de nuestras instituciones públicas que no han experimentado similar transformación a fin de conseguir un sector público que racionaliza sus recursos y que ha de optimizar sus resultados a fin de constituirse, más que en una rémora, en esa infraestructura imprescindible que proporciona credibilidad y seguridad en el cumplimiento de sus compromisos de servicio a la sociedad en su conjunto y a cada uno de los ciudadanos para mantener la capacidad de supervivencia y competitividad del país en el mundo globalizado e interdependiente en el que nos movemos.

Este cambio de perspectiva, como se ve en cierto sentido impuesta por un conjunto de circunstancias, obliga a replantear nuestro sistema de empleo público que, globalmente, parece más pensado para responder a las necesidades de una sociedad y a una Administración de otra época, pero no de la era post-industrial, tecnológica y telemática, cambiante y de incertidumbre en que nos movemos en la actualidad. Una era, por utilizar un término que se ha popularizado, disruptiva que nos obliga a despojarnos de visiones ancladas en el pasado (una época VUCA).

Se hace precisa la introducción de nuevas claves y de nuevas herramientas y despojarnos de ciertos mitos y tabúes para afrontar la exigencia de resultados que una sociedad madura y desarrollada plantea a nuestras Administraciones públicas. Es necesario, pues, un nuevo concepto de responsabilidad que realce, al menos en igual medida, la consecución de metas y objetivos con el respeto ineludible y necesario en una sociedad democrática a los principios de legalidad y de seguridad jurídica. Es decir, es preciso que pensemos sobre el exceso de reglas formales en nuestros procedimientos (derivadas, bien es verdad, de la desconfianza existente hacia nuestros responsables públicos que en más de una ocasión, como hemos podido apreciar en los últimos años, la justifican) y los efectos contradictorios, y en algunos casos meramente retóricos, que pueden provocar, con la ausencia, en forma paralela, de mecanismos reales de exigencia de responsabilidad basada en los resultados para nuestros responsables y servidores públicos. La pandemia ha tenido la virtud de mostrar carencias de las que deberíamos sacar conclusiones (tramitación de lo denominadas «ertes» o del ingreso mínimo vital entre otras cuestiones). 
Como se ha puesto de relieve en algunos informes (Catalá y Cortez, 2020) es ahora cuando el déficit de renovación de nuestras Administraciones empezará a pasar factura a fin de enfrentar los retos que está planteando esta pandemia y la subsiguiente crisis fiscal que nos aguarda a la vuelta de la esquina ${ }^{5}$. Bien es cierto que no solo esos retos han de enfrentarse, sino que también hay otros de carácter estructural en este nuevo siglo que por sí solos ameritarían replantearnos una profunda reforma y a los que seguidamente nos referiremos.

\section{LOS RETOS Y TENDENCIAS QUE MARCARÁN LA ADMINISTRACIÓN PÚBLICA Y EL EMPLEO PÚBLICO EN LA PRÓXIMA DÉCADA(S)}

Como ha puesto de relieve Ramió (2017) la Administración pública no es una variable independiente sino una variable muy dependiente de otras como la economía, la sociedad, la política y la tecnología. Su hipótesis es que el estudio de la Administración pública solo puede avanzar, para lograr un futuro perfecto, si se vincula más con la economía y con la sociedad, dado que los desafíos de las administraciones públicas son institucionales y guardan relación directa con los grandes problemas y retos económicos, políticos, tecnológicos y sociales.

Pues bien, si admitimos que un Buen Gobierno es aquel que en sus procesos de producción de políticas públicas genera valor añadido realizando correctamente su función también coincidiremos en que ese proceso se materializa en dos direcciones fundamentalmente: en primer lugar, generando bienes públicos pertenecientes a todos que permitan mejorar las condiciones de vida del cuerpo social; $y$, en segundo lugar, dando respuesta a las demandas de la ciudadanía.

También se hace evidente que la necesaria reforma del Estado para conseguir un Buen Gobierno asimismo transciende a la Administración como «instrumento primario de éste en la acción de configuración e integración sociales» ${ }^{6}$. La crisis del Estado del bienestar, de las formas clásicas de intervención pública, ha arrastrado a redefinir el perfil de la Administración pública. Y es que, como señala Schmidt-Assmann (2001: 25), si los Estados son esencialmente Estados administrativos, resulta entonces evidente que las grandes transformaciones que en la actualidad están sufriendo tanto el Estado, la economía y la sociedad, van a producir a su vez -y de hecho se están produciendo-importantes y variadas consecuencias respecto a las Administraciones públicas. La actual situación de la Administración, expresa con acierto dicho autor, se encuentra así determinada por la idea de transformación.

El Estado europeo occidental viene atravesando un largo periodo de transición. El desarrollo del modelo económico, social y político y la crisis económica han venido generando nuevas condiciones en las que el modelo de Estado, hasta ahora indiscutido, se revela no suficientemente adecuado para conducir los procesos sociales y resolver los problemas derivados de la convivencia. La vertiginosa evolución social ha venido poniendo en tela de juicio los principios y categorías en los que el Estado basaba su organización y está haciendo emerger nuevos mecanismos y nuevas técnicas de gestión alternativas a las hasta ahora conocidas por nuestros sistemas de actuación administrativos para hacer frente a las exigencias que las transformaciones sociales plantean.

Concretamente, y como ha señalado Schmidt-Assmann (2001: 6), la crisis del Estado de bienestar se ha proyectado sobre las Administraciones de tres formas distintas. En tanto crisis de recursos, conduce a una reducción de medios económicos, personales y materiales que, a su vez, exige una mayor economía en la Administración de los recursos disponibles. De esta forma, se indica que las consideraciones relativas a la eficiencia, al tiempo y a los costes desempeñan en la actualidad un papel más relevante en la ejecu-

5 Destacan dichos autores que «La reforma del empleo público es una de las reformas pendientes que tiene nuestro país. Aunque en las últimas décadas se han sucedido los cambios legales la realidad es que, en lo sustancial, el modelo ha permanecido inalterable desde su nacimiento en el siglo XIX y el posterior Estatuto de Maura de 1918. Son diversas las razones que han impedido avances en esta dirección: los diferentes ritmos de la policy y las politics, el desgaste que supone una reforma complicada y de réditos inciertos, los intereses corporativistas o la fragmentación competencial de nuestro modelo son algunas de ellas».

6 Véase PAREJO ALFONSO. L. (1991): Crisis y renovación en el Derecho Público, pág. 22. Madrid: CEC. Asimismo, sobre la crisis del modelo de Estado puede consultarse, entre otros, el estudio de PAREJO ALFONSO. L. (1999): "El Estado como poder y el derecho regulador de su actuación, hoy; algunas de las transformaciones en curso", en Revista del Clad. Reforma y Democracia, núm. 15, pág.145, en donde se afirma que existe en todo caso una puesta en duda de la configuración y papel establecidos del Estado y, por tanto, una demanda de transformación de éste en un contexto de convivencia y pugna entre ideas y tendencias contrapuestas o, al menos, diferentes, con la consecuencia de una notable desorientación tanto sobre los medios como sobre los fines. 
ción de programas administrativos y en su momento sirvieron para el desarrollo por parte de la doctrina del new public management. De otro lado, esa crisis del Estado de bienestar ha motivado un «replanteamiento crítico del catálogo de tareas administrativas» que, en distintos sectores, dieron lugar a intensos procesos de privatización. Por último, y en tercer lugar, la crisis del Estado social también es la crisis del concepto clásico de «dirección» e indica dicho autor que los instrumentos regulatorios del Derecho Administrativo que hemos heredado como las órdenes o prohibiciones formalizadas en actos administrativos, no parecen ser ya suficientes, o al menos no parecen serlo por sí solos. Ello conduce a la necesidad de complementar los instrumentos de dirección tradicionales con técnicas de actuación administrativa informal y cooperativa.

En cualquier caso, es preciso subrayar que existe una cierta coincidencia en la insolvencia del instrumental que las Administraciones públicas tienen a su disposición para hacer frente a este conjunto de retos. $Y$ es que si el Estado asume nuevas funciones que le demandarán esos retos será necesaria una renovación de las herramientas de que se sirve para dar respuesta a éstos. Todo ello ha provocado que desde un sector doctrinal se apunte que los principios básicos del Derecho Administrativo y los fundamentos de la actual gestión pública pertenecen, en parte, al Estado Liberal lo cual supone una disfuncionalidad que debe ser superada.

En definitiva, nos enfrentamos al complejo reto de adecuar nuestras Administraciones a la nueva situación que demanda la actual realidad económica y social que además es interdependiente del contexto internacional. $Y$ es que, en efecto, la gobernanza nacional cada vez es más dependiente, en la práctica subordinada, de las decisiones que se toman en el exterior. Un mundo global interdependiente con diversos actores que tienen intereses transnacionales e intersectoriales, así como el surgimiento de una conciencia global y un nuevo contrato social para la ciudadanía, están cambiando el proceso de toma de decisiones y aumentando la necesidad de una cultura anticipadora de elaboración de políticas.

Y cuando se ha planteado como será la Administración del futuro, desde la academia, se han avanzado distintas líneas sobre las que se asentará esta. Así Uvalle Berrones (2009) señala las siguientes: 1. democratización de la administración, 2. relación principal-agente, 3. visión de redes, 4. gestión y responsabilidad, y 5. implementación de capacidades públicas. Ramió (2017), por su parte, estima ineludible una nueva ética y valores de carácter público que contribuya a la renovación de la cultura institucional y pone así en el centro del debate un listado de valores (ética, sostenibilidad, transparencia, coherencia política, valentía...) que deberían ser tenidos en cuenta en la definición de un buen modelo democrático y un buen sistema de gobernanza compleja. E indica, asimismo, entre otras, un conjunto de tendencias que se vislumbran para afrontar los retos del futuro, a saber: los nuevos roles que el Estado ha de desarrollar, el previsible establecimiento de una gobernanza institucionalizada e inteligente: modelo en red de metagobernanza (dominado por el ámbito público en el que las instituciones públicas asumen el rol de metagobernador) de elevada institucionalización e innovación, el incremento de la colaboración público-privada, la necesaria renovación de las arquitecturas organizativas actuales y la superación del déficit en liderazgo político.

Desde nuestro punto de vista, y aunando distintas visiones sobre las tendencias de los aparatos administrativos, los próximos años dibujarán una Administración presidida por las siguientes tendencias que, aunadas todas y las interacciones que generan entre sí, ofrecen un marco necesario para articular las respuestas que nuestro sistema de empleo público debe ofrecer:

\section{Una Administración más democrática: gobierno abierto, participación ciudadana y redes sociales.}

La crisis del Estado y de la Administraciones pública conduce a su replanteamiento; a una nueva concepción de la actuación de la Administración y de su relación con el ciudadano. La necesidad de mejorar las relaciones entre los ciudadanos y la Administración es considerada en todos los países como una obligación inexcusable que ha de constituir un objeto irrenunciable de los diferentes procesos de reforma de las Administraciones públicas.

El modelo burocrático aún subsistente garantiza valores que han de permanecer en cualquier caso y que deben ser valorizados. La eficiencia, impersonalidad, profesionalización y sujeción al Estado democrático de éste y su sujeción al Estado de derecho siguen siendo valores útiles del sistema. Siendo útiles son seguramente un tanto insuficientes para asegurar la participación de la ciudadanía en las labores públicas. Y es que la Administración pública burocrática de tipo tradicional, por si misma, no tiende a establecer un sistema que permita su apertura y accesibilidad para que sea conocida en el espacio de lo público. Sin embargo, la profundización democrática de nuestra Administración exige articular normas, reglas y procedimientos, cuyo objeto sea acercar la administración pública a los ciudadanos, en un ejercicio abierto que consiga formas de comunicación para que las estructuras de operación no sean ajenas ni distantes a éstos. 
Como consecuencia del grave problema del descrédito de instituciones y representantes políticos en España se ha reforzado la exigencia de eficacia y responsabilidad en la acción de gobierno. Para ello, se hace necesario el fortalecimiento de la democracia a través de mecanismos permanentes de gobierno abierto, control de la transparencia, y rendición de cuentas, a la vez que se trata de fomentar en la gobernanza valores positivos como la ética, la flexibilidad y la eficacia. De esta forma, en el modelo de gobernanza que se propugna el papel que se le atribuye a los ciudadanos es diferente pues dejan de representar un papel pasivo receptor de prestaciones y servicios para la satisfacción de sus necesidades para ser sujetos de derechos y deberes. De esta manera, se da un tránsito en su consideración de usuario cliente a ciudadano activo. Se trata de un ciudadano que tiene una dimensión individual propia pero también una dimensión social. En este sentido, la gobernanza se caracteriza, entre otros extremos, por un involucramiento de la ciudadanía para afrontar los retos sociales, ya que una buena gobernanza necesita de una ciudadanía activa y comprometida con lo público, por lo que se precisa disponer de canales de participación en la toma de decisiones (Pascual Esteve, 2011: 90, 97 y 99)7. La idea es transitar del concepto de atención ciudadana para sustituirlo por el de interacción con la ciudadanía.

En suma, la transparencia y la participación ciudadana se han erigido en un aspecto prioritario y transversal. Se requiere de un modelo de administración pública capaz de generar redes y de escuchar, atender y compartir las demandas de la ciudadanía. La participación ciudadana se encuentra en el núcleo mismo de la idea de democracia: diálogo con la ciudadanía para abordar los problemas, escuchar y compartir las soluciones.

En este sentido, se da paso a una nueva funcionalidad de la Administración, la cual al gestionar los intereses colectivos debe propiciar medidas que impliquen la colaboración de los ciudadanos, ya que la Administración no es dueña del interés público sino que está llamada a articular una adecuada intercomunicación con los agentes sociales para definir las políticas públicas; quiere esto decir que los ciudadanos no deben ser solo sujetos pasivos de las potestades públicas, sino que deben aspirar a ser legítimos colaboradores y protagonistas de la Administración para la gestión de los propios intereses que les afecten.

Es necesario, por ello, generar nuevos mecanismos para la implicación de la sociedad civil en los asuntos públicos, como coformuladora y coproductora en las políticas sociales, e incluso cogestora de servicios públicos. Esta participación mejoraría, además, el nivel de información que tienen los responsables públicos en relación a las necesidades y las demandas de la ciudadanía. Ha de apostarse por políticas sociales con liderazgo de la acción social colectiva (status sociales); innovación social que incluya nuevos productos y servicios (por ejemplo, la economía compartida); nuevos procesos (como los de cocreación), nuevas normas y reglamentos y nuevas formas organizativas (por ejemplo, las empresas sociales).

De otro lado, en el marco de las Administraciones públicas las redes sociales han pasado a formar parte de un ecosistema para difundir y comunicar mejor, como herramienta de transparencia, de participación ciudadana en el ámbito del gobierno abierto o como herramientas para mejorar las relaciones con la ciudadanía. En los últimos años se han empezado a publicar estudios sobre cómo es o debería ser el papel del sector público en el entorno 2.0 y ya empieza a existir bibliografía sobre aspectos teóricos y buenas prácticas en este ámbito.

Ahora bien, si en general se empezaron a utilizar como herramientas que complementaban y ampliaban el abanico de posibilidades de comunicación con una finalidad de llegar a un colectivo de ciudadanía que no tenía la web institucional como herramienta habitual de consulta y relación dado que tradicionalmente utilizaba las propias redes sociales como herramientas para otros ámbitos de su vida, su funcionalidad ha ido transmutándose de ser meras herramientas de comunicación para pasar a ser herramientas que reducían la distancia entre la ciudadanía y las administraciones públicas, generando «una confianza social y política indispensable para avanzar social y económicamente».

En la actualidad, y en definitiva, las redes sociales han ampliado su radio de acción y se utilizan, junto con la comunicación, para conseguir otras finalidades de mayor alcance: el gobierno abierto, la transparencia, la cocreación de servicios públicos con la ciudadanía y como un nuevo elemento de cambio e innovación para transformar la prestación de servicios públicos para crear nuevo valor público. Para Graells y Ramilo

Asimismo, sobre el papel de la participación ciudadana en la gobernanza puede consultarse el capítulo 11 de dicho estudio titulado "Participación y compromiso cívico de la ciudadanía", págs. 271 y ss. Este autor diferencia los planteamientos de participación propios del gerencialismo público -centrados en la provisión de los servicios financiados con fondos públicos y su gestión- de los sistemas de participación en gobernanza democrática, o modelos de deliberativo-relacionales, que buscan el compromiso y colaboración de los sectores ciudadanos con la ciudad o región, págs. 296 y ss. 
(2013) trabajar en red supone un notable cambio en la manera de hacer las cosas y de dirigirse a los ciudadanos y ello requiere la adopción e implantación de nuevos principios de actuación por parte de los trabajadores públicos tales como la ubicuidad, la colaboración, la transparencia, la proactividad, etc. así como la horizontalidad, la igualdad o la universalidad en el acceso a la información.

Las redes sociales se pueden convertir, en este sentido, en una potente herramienta al servicio del open government, fomentando la creación de unas instituciones públicas mejor informadas, más innovadoras, más centradas en la ciudadanía y, por tanto, más democráticas. Y ello exige nuevos perfiles y habilidades en los empleados públicos.

\section{Una Administración con nuevos principios, valores y derechos: el derecho al patrimonio público.}

Las necesidades que la sociedad percibe, los valores, la visión respecto de que bienes son deseables y cuáles imprescindibles varían en el tiempo y es por ello que el Derecho debe ser dinámico para adaptar su concepción de justicia a las exigencias de la sociedad, y de regular las formas de hacer y proceder de los poderes públicos, por lo que debe ser acompañado y acompañar la evolución de las otras ciencias sociales: la sociología, la historia, las ciencias políticas y por supuesto, la economía. Pues bien, en estos momentos el Derecho, y muy singularmente el Derecho administrativo, está llamado a dar respuesta a la nueva sensibilidad social surgida durante la crisis económica que reclama una mayor ética pública y unos derechos de la ciudadanía a exigirla.

En momentos como los actuales la ciudadanía exige derechos que, hasta ahora, o creíamos salvaguardados por los poderes públicos, o, mucho más sencillo, no nos imaginábamos como actores de los mismos. Así ha sido históricamente con otros derechos como los derechos civiles, políticos o sociales y así ocurre en la actualidad con los derechos supraindividuales o colectivos. Desde los trabajos de Skinner (1978) y Pettit (1997) en torno al denominado «republicanismo» parece preciso incorporar a la lógica de construcción del Derecho administrativo la idea de que la democracia implica una afirmación de la ciudadanía tendente a buscar el equilibrio entre los derechos individuales y colectivos, entre el campo de lo público y lo privado, entre los valores republicanos, liberales y sociales.

Y ello implica, de forma necesaria, el reconocimiento de derechos de la ciudadanía que van más allá de los que hasta el momento habían sido reconocidos. Efectivamente, y como inclusive con anterioridad pusiera de manifiesto Marshall (1950), uno de los procesos sociales más significativos en la extensión del poder y el alcance de las actividades del Estado ha sido la ampliación de los derechos de ciudadanía. Por derechos de ciudadanía, a juicio de Marshall, han de entenderse aquellos derechos que acumula una persona simplemente por ser un ciudadano de la nación. Y de esta forma, el desarrollo de la ciudadanía supuso históricamente la afirmación progresiva de los derechos civiles, posteriormente de los derechos políticos y, a continuación, de los derechos sociales ${ }^{8}$. Y aún cuando, ciertamente, los mismos no hayan alcanzado plenamente su efectividad, no es menos cierto que desde la mitad del pasado siglo se han alumbrado nuevos derechos, los también denominados derechos republicanos, que aún no han sido, al menos en todos los supuestos, refrendados legalmente y efectivamente ejercidos, si bien lo cierto es la afirmación de una efectiva tendencia dirigida hacia su progresivo reconocimiento y protección por el Derecho.

El concepto de ciudadano se ha ido desarrollando progresivamente en la medida en que los individuos adquirían derechos y extendían su participación a la creación de la ley. Dicho proceso, que se aleja de los derechos naturales, no es sino el resultado de una lucha histórica en virtud de la cual los individuos y los grupos sociales han luchado por su afirmación. De esta forma, a finales del siglo XX, y como también ha puesto de relieve Bresser-Pereira $(2001)^{9}$, ya se mantenía que ha aparecido un cuarto tipo de derechos: los derechos de la ciudadanía (protección del ambiente, el derecho a la ciudad, el patrimonio público, etc.).

\footnotetext{
8 Aunque debe advertirse que, sin perjuicio de lo expuesto, HABERMAS, J. (1992): Between facts and norms. Cambridge, MA: The Mit Press, ha advertido que el análisis de Marshall explica una historia lineal que no hace hincapié en la importancia de los derechos políticos y expone que «De hecho, sólo los derechos de participación política fundamentan el marco legal de los derechos reflexivos y autoreferidos de los ciudadanos. Las libertades negativas y los derechos sociales pueden, en comparación, ser concedidos por una autoridad partenalista. En principio, el Estado Constitucional y el Estado de Bienestar son posibles sin una Democracia».

9 Ya desde la segunda mitad del siglo XX surgieron en diversos documentos de Naciones Unidas los denominados derechos de tercera generación que incluían elementos tales como la solidaridad, la paz o el desarrollo económico, aunque como ha puesto de relieve $\mathrm{BOBBIO}$ éstos no son sino una categoría que es aún muy imprecisa y vaga. Contemplan cuestiones de carácter supranacional como el derecho a la paz, a un medio ambiente sano, a la identidad nacional y cultural, a la justicia internacional, al uso de los avances de las ciencias y la tecnología, a la protección del patrimonio común de la humanidad, al desarrollo sustentable, etc.
} 
Si los derechos civiles son derechos individuales, que protegen al individuo mientras éste persigue su propio beneficio, los derechos republicanos son derechos colectivos que protegen a la colectividad. De esta forma, los derechos republicanos se manifiestan, entre otros supuestos ${ }^{10}$, y junto a que los ciudadanos tienen derecho a que la res pública siga existiendo y sirviendo a todos más que ser apropiada por grupos patrimonialistas o corporativistas que actúan en la sociedad como «buscadores de rentas» (rent-seeking agents), en otros que como el espacio urbano, el patrimonio histórico o el medio ambiente se corresponden con bienes jurídicos cuya titularidad es compartida por la ciudadanía.

Estos derechos, por tanto, de carácter colectivo son, sin embargo, derechos ejercitables individualmente en la medida en que cada individuo es portador de éstos y, en esa misma medida, debiera tener legitimación para defenderlos.

Específicamente ha de hacerse referencia al derecho al patrimonio público como derecho supraindividual que se manifiesta en los derechos de los ciudadanos a defenderse de aquellos que intentar apropiarse, de manera individual, de los bienes que pertenecen o deben pertenecer a todos (Bresser Pereira, 2001: 7). Forma parte éste de ese conjunto de derechos republicanos que surgen con la universalización del proceso de democratización que exige a los ciudadanos un mayor interés por los asuntos públicos y que demandan un mayor control social del ejercicio del poder público.

Y es que la corrupción es una de las cuestiones más erosivas de nuestro tiempo. Las agencias internacionales han puesto de relieve que malgasta los recursos públicos, aumenta la desigualdad económica y social, alimenta el descontento y la polarización política y disminuye la confianza en las instituciones. De esta forma, y en general en el mundo contemporáneo, pero por sobre todo en las democracias avanzadas se observa un crecimiento importante del interés por una nueva ética pública o ética de las instituciones públicas y, por tanto, de la extensión de unos valores y normas de conducta a quienes son servidores públicos y deciden, gestionan o administran bienes y servicios públicos ${ }^{11}$. A imagen y semejanza de las políticas empresariales que se impulsaron desde mediados de la década de los noventa del siglo Xx sobre «buen gobierno corporativo», también en el sector público la irrupción en escena de la ética institucional ha sido intensa en los últimos años.

\section{Una Administración digital.}

El desarrollo de las nuevas tecnologías ha influido sustancialmente en cómo realizamos muchas de nuestras actividades diarias. Así, entre otras cosas, ha modificado nuestra forma de comunicarnos, de buscar información y archivarla; cómo disfrutamos del tiempo de ocio; e incluso en la forma de desempeñar nuestra actividad laboral (y sino véase la irrupción del teletrabajo o cómo desarrollamos en la actualidad la actividad investigadora)

De esta forma, entre las grandes tendencias a las que habrá de enfrentarse la Administración destacan de forma relevante el desarrollo de tecnologías disruptivas y los cambios tecnológicos que impulsan nuevos paradigmas de relación de la ciudadanía con las Administraciones y la reutilización eficiente de información que implicarán, a buen seguro, cambios en el sector público tal y como hoy lo conocemos. A título de ejemplo, el uso de chatbots basados en el procesamiento del lenguaje natural como primera interfaz entre los ciudadanos y las AA.PP permite ya -por ejemplo en EE.UU- reducir los tiempos de respuesta y aumentar las capacidades de focalizar a los funcionarios públicos en tareas de más valor social.

La Administración digital, por esta y otras razones, ya no es una opción. Parece evidente-legalmente ya resulta exigible en distintos ordenamientos-, que los servicios electrónicos son irrenunciables en la actualidad y lo van a ser todavía más en el futuro próximo. Si, como ha puesto de relieve la Fundación Telefónica (50 estrategias para 2050: el trabajo y la revolución digital en España), se reclama un papel ejemplarizante del sector público, con un uso intensivo de tecnología y aplicación de soluciones a los servicios y retos socia-

10 Al menos tres derechos republicanos deben ser señalados en la actualidad, a juicio de (BRESSER-PEREIRA, 2001), el derecho al patrimonio medioambiental y urbano, el derecho al patrimonio cultural y, por último, el derecho al patrimonio económico-público que hasta ahora se han manifestado, con carácter general en el Derecho público como intereses difusos, pero que reclaman su conversión en derechos y que inciden en la defensa de esos bienes colectivos.

11 Los riesgos en materia de integridad están presentes en las distintas interacciones entre el sector público y el sector privado, la sociedad civil y las personas físicas, en todas las fases del proceso político y del ciclo de elaboración de políticas públicas, por lo que esta interconexión exige de un enfoque integrador que abarque al conjunto de la sociedad a la hora de mejorar la integridad pública y reducir la corrupción dentro del sector público. Disponer de una adecuada infraestructura para la integridad resulta crucial para la gobernanza pública, salvaguardando el interés general y reforzando valores fundamentales como el compromiso con una democracia plural basada en el imperio de la ley y el respeto a los derechos humanos. 
les (compra pública), promoción directa de startups tecnológicas y otras políticas de apoyo, el sector público, ahora como empleador, deberá plantearse qué implica la digitalización en su forma de funcionar y añadir valor en sus procesos de producción de políticas. Su demanda, por demás, por parte de la ciudadanía será cada vez mayor, aunque es preciso recordar que su implementación no puede de ninguna manera mermar los derechos y garantías de los ciudadanos ${ }^{12}$. Se ha de realizar con la mirada puesta en éstos y no en el sistema burocrático como desgraciadamente tantas veces ocurre digitalizando la burocracia y no simplificando y haciendo accesible los trámites a los ciudadanos.

El mantenimiento y la evolución de los servicios electrónicos, y la incorporación de la inteligencia artificial, y muy especialmente el análisis de datos, a los procesos y procedimientos administrativos ${ }^{13}$, es ahora el mantenimiento y evolución de la propia actividad administrativa que a buen seguro será predominantemente digital y el reto es gestionarlos con la máxima eficiencia dado que el proceso de digitalización de los servicios públicos y la tramitación electrónica de los procedimientos permite también mejorarlos, simplificarlos, estandarizarlos, sistematizarlos y automatizarlos. Y es que, como se pone de relieve en el Plan España Digital 2025, tecnologías como la Inteligencia Artificial, el blockchain, o la explotación de la información a través del big data, nos dirigen hacia una Administración Pública «data-driven», en la que la personalización de los servicios o conceptos de relación con la ciudadanía como Ciudadano $360^{\circ}$ son clave.

Por lo que se refiere al modo y forma de desarrollar el trabajo en la Administración de los próximos años, actualmente no sólo en el quehacer profesional precisamos el uso de herramientas informáticas diversas para realizar nuestras tareas, sino que incluso las actuales tecnologías de la información y la comunicación han permitido que quien trabaja pueda desarrollar su actividad fuera del centro de trabajo, lo que se ha dado en llamar trabajo «a distancia» o teletrabajo lo que, sin duda, tendrá, una vez que se generalice, implicaciones en las fórmulas organizativas y de producción de políticas públicas que todavía tenemos en la Administración optimizando recursos y automatizando procesos. Ello sin contar con la incidencia en los perfiles de empleados públicos que necesitaremos en un futuro que ya está ahí -y la necesaria adaptación de los que tenemos en el presente- y que nos reclama competencias digitales de éstos, nuevas fórmulas de vinculación y organización de los mismos y una gestión de los recursos humanos mucho más flexible que el demandado por el modelo de Administración analógica todavía existente.

La denominada e-Administración va hoy mucho más allá de la mera gestión electrónica de trámites administrativos, y se asocia decididamente a la mejora de los servicios públicos y de la comunicación entre ciudadanía y gobernantes. Como detalla el Plan España Digital 2025 la mera existencia de servicios electrónicos no produce eficiencia ni reducción de cargas administrativas, sino que requiere de una modernización de procesos y adaptación de los canales para lograr un uso masivo eficaz, y seguro por ciudadanía y empresas.

\section{Una Administración inclusiva.}

a) Una Administración para todos.

El insuficiente acceso de determinados grupos a las administraciones tiene efectos en los contenidos de las políticas: lleva a unas políticas de menor calidad -en la medida que ignoran las visiones, expectativas, necesidades e intereses de parte de la población-, a la vez que puede contribuir a aumentar la percepción de lejanía en determinados sectores de la ciudadanía y generar una menor propensión a asumir estas políticas.

12 Cabe traer a colación la STS de 16 de de noviembre de 2011 (rec. 2841/2015) que ya advertía que no supone un cambio de paradigma la Administración electrónica en lo que se refiere a los derechos y garantías que el procedimiento administrativo establece para la ciudadanía.

13 En el caso de Europa se aprobó Libro Blanco sobre la Inteligencia Artificial: un enfoque europeo orientado a la excelencia y la confianza [COM(2020) 65 final] que,en el caso español, se ha traducido en la aprobación de la Estrategia Nacional de Inteligencia Artificial y, de forma previa, en el Plan España Digital 2025. Se destaca en ésta que la iniciativa permitiría: formular un Plan de Datos Nacional con actualizaciones periódicas; definir una gobernanza, estructura organizativa y procedimientos interministeriales; definir un conjunto de reglamentos, normas y procedimientos alineados con las directivas de la UE; analizar la reutilización y explotación de datos abiertos del sector público; la explotación de los datos abiertos y cerrados utilizando técnicas de IA; ofrecer un punto de contacto para aconsejar a las AA.PP en las estrategias a realizar para conocer cómo extraer nuevo conocimiento de los datos utilizando técnicas de IA; ofrecer una formación especializada en IA a los trabajadores públicos para poder sacar el máximo partido a los datos que disponen, y así contribuir a la mejora de las Políticas Públicas; establecer los cauces mediante los cuales las empresas privadas pueden o deben compartir parte de sus datos con la Administración Pública con el objetivo de ofrecer mejores servicios públicos y crear colaboraciones público-privadas en las que se compartan datos que permitan ofrecer servicios innovadores de valor añadido, siempre respetando las regulaciones de privacidad y protección de datos, en beneficio de la ciudadanía y del funcionamiento de las administraciones públicas. 
El establecimiento de cuotas de acceso ha sido, y sigue siendo, el principal instrumento con el que se ha avanzado, en nuestro país, en el acceso e inclusión de las personas con discapacidad en el empleo público. Lo mismo podría decirse de otros colectivos como notoriamente resulta con la inmigración bien que con estrategias variables en unos y otros casos.

Será preciso redefinir el siempre difícil equilibrio entre las medidas de acción positiva tendentes a garantizar la igualdad de oportunidades y el compromiso con los principios constitucionales de mérito y capacidad. Efectivamente, el imprescindible respeto a los principios de mérito y capacidad no debe pasar, necesariamente, por establecer los mismos umbrales y las mismas pruebas de acceso (o provisión o promoción interna) a las personas con y sin discapacidad (igual podría decirse de otros colectivos). Aquí radica la cuestión esencial. Establecer pruebas distintas, con notas de corte diferentes, tiempos adicionales y otras medidas de apoyo, no implica, cuando se trata de personas con discapacidad a título de ejemplo, una vulneración de los principios de mérito y capacidad. Todo lo contrario. Se trata de medidas plenamente justificadas que las Administraciones están obligadas a implementar para garantizar la igualdad de oportunidades y el pleno desarrollo de los artículos 9.2, 14 y 49 de la Constitución Española.

b) La decisiva incorporación de la perspectiva de género en la producción de políticas públicas y en la organización de nuestro empleo público.

Las políticas de igualdad entre mujeres y hombres en las administraciones públicas tienen ya un notable recorrido ${ }^{14}$.

El análisis general de las herramientas del mainstreaming muestra que la estrategia ha dado lugar a cambios en las estructuras, rutinas y resultados de las diferentes administraciones. Se ha generalizado la utilización de muy diversos mecanismos que sin duda pueden facilitar que sea puesta en práctica de manera efectiva. De hecho, el enfoque adoptado ha resultado bastante similar en todos los niveles de gobierno de modo que instrumentos como los informes de impacto o los consejos participativos tienen presencia en casi todo el territorio.

Ahora bien, la igualdad efectiva de mujeres y hombres en el ámbito de la Administración pública, si se pretende que sea cada vez más real y, en consecuencia, que en forma paulatina, se empiece a ir difuminándose la segregación horizontal y vertical, el techo de cristal y sobre todo la brecha salarial entre mujeres y hombres cuya existencia hoy evidencia cualquier estadística que se realice al respecto, requiere de distintas consideraciones a las realizadas hasta ahora.

Son muchos los factores que deben tomarse en consideración a ese respecto y sin duda este no es ni el momento ni el lugar para hacer una enumeración exhaustiva y detallada de todos los extremos que deberían ser objeto de modificación a los efectos que aquí interesa, pero si se puede apuntar que requiere de medidas que afectan al acceso al empleo público; medidas referentes al desarrollo de la prestación de servicios; y medidas que tienen que ver, inclusive, con el cese o el despido del personal ${ }^{15}$.

5. Una Administración más flexible: nuevas arquitecturas organizacionales más orientadas a la consecución de resultados.

A lo largo de estas líneas hemos ido poniendo de relieve que la Administración debe ofrecer el mejor servicio posible a la ciudadanía en un contexto que, como también se ha puesto de manifiesto, es cambiante e incierto. Abordar una nueva concepción de la organización de la Administración que se adecúe mejor a las nuevas formas de trabajo requeridas por la utilización generalizada de los medios electrónicos, por la

14 En un primer momento se centraron en corregir la desigualdad de trato entre hombres y mujeres característica de las democracias liberales, que habían excluido a las mujeres de la esfera pública, tanto del sufragio como del acceso a muchas profesiones. A raíz de la segunda ola del feminismo, en los años 80 del siglo xx, se hizo patente la insuficiencia de la igualdad de trato a la hora de conseguir una verdadera igualdad de oportunidades, por lo que se empezaron a implantar políticas específicas y de acción positiva dirigidas a las mujeres. Se desarrolló así la política de igualdad de género como un ámbito sectorial de intervención, con sus herramientas (los planes de igualdad, fundamentalmente) y sus instituciones específicas (mayormente los Institutos de la Mujer en el contexto español). Sin embargo, a lo largo de los años se fue constatando también la insuficiencia de este enfoque sectorial de intervención para abordar un fenómeno tan multidimensional, estructural y resistente al cambio como es la desigualdad de género. Por ello, con ocasión de la Cuarta Conferencia Mundial sobre la Mujer de Naciones Unidas celebrada en Beijing, en 1995 se lanzó a nivel mundial la estrategia del mainstreaming de género, la cual significó un paso adelante en el compromiso con la igualdad. Este nuevo consenso mundial sobre cómo afrontar la desigualdad entre mujeres y hombres se ha ido incorporando progresivamente a los principales marcos normativos a nivel nacional e internacional, entre ellos el Tratado de Ámsterdam de la UE.

15 Muy interesante, a este respecto, es el Libro Violeta de la Función Pública Valenciana, (SEVILLA MERINO, J.; BELANDO GARÍN, B.; FABREGAT MONFORT, G.; GARCÍA CAMPÁ, S., 2017). Valencia, Gobierno de la Generalitat Valenciana. 
creciente importancia que la participación ciudadana adquiere en el ciclo de las políticas públicas y por la adopción de nuevos sistemas de gestión orientados a la consecución de resultados para la ciudadanía, resulta hoy una tarea ineludible y necesaria.

Factores como la globalización de los mercados, la difusión de la infotecnología y las incertidumbres inherentes a estos fenómenos han contribuido a que muchos autores señalen la obsolescencia de las formas organizativas tradicionales y la necesidad de cambiar las estructuras para adaptarlas al nuevo entorno. Las estructuras organizativas que han venido soportando el modelo actual deben adecuarse a las nuevas tareas que requieren la implantación del nuevo modelo de innovación y Administración digital. Impulsar la integración de servicios, descubrir las necesidades y preferencias de la ciudadanía e involucrar a la ciudadanía en el diseño de los servicios se señalan como actuaciones a seguir.

De esta forma, en los últimos años, han proliferado los estudios que avanzan en el desarrollo de nuevas formas organizativas para las Administraciones en el contexto de las economías desarrolladas. Para Ramió (2017) las nuevas organizaciones públicas podrían tener unas arquitecturas variables que combinen unas potentes unidades centrales con unos parques logísticos de servicios públicos. Las unidades centrales, relata el autor referido, tendrían un carácter político, de inteligencia y de supervisión de los parques logísticos y éstos tendrían, por su parte, un carácter especializado en el diseño preciso de las políticas públicas y en la producción y prestación de los servicios públicos. Las unidades centrales tendrían tres funciones básicas: contacto directo con la ciudadanía para lograr una mayor legitimidad democrática, competencias de inteligencia consistentes en traducir las intenciones políticas en políticas y servicios públicos concretos y, finalmente, el ejercicio de las funciones de «principal» ante una red de agencias públicas y de agentes privados que serán los ejecutores de las políticas públicas.

De esta forma, y en opinión de dicho autor, las instituciones públicas agruparían también a unos parques logísticos de servicios públicos muy parecidos a los actuales parques industriales ubicados en los arrabales de las áreas metropolitanas o incluso fuera de ellas (en áreas rurales cercanas a los territorios metropolitanos) organizados por sectores de políticas y servicios públicos en los que confluyeran físicamente algunas agencias públicas independientes vinculadas a determinadas administraciones municipales, metropolitanas, regionales, estatales e incluso internacionales con una red de organizaciones privadas, con ánimo y sin ánimo de lucro, especializadas en el desarrollo y en la prestación de políticas y servicios públicos.

Lo cierto, y en esto hay una cierta coincidencia, es que estas nuevas formas organizativas estarían enfocadas hacia el aprendizaje continuo, el desarrollo de las capacidades esenciales de la organización y la flexibilidad. Y así, ciertamente, en los últimos tiempos se han ensayado distintas alternativas en la gestión de servicios públicos: introducción de contratos programa y contratos de gestión, transformación de la forma jurídica de los servicios públicos mediante su conversión en entes de Derecho público y dotación de personalidad jurídica (fundaciones, consorcios, entidades públicas, etc.), desarrollo de formas innovadoras de contratación externa o gestión indirecta con proveedores privados (lucrativos y no lucrativos), etc.

En todo caso, el eje común de las nuevas estructuras es la flexibilidad, lo que a priori denotaría un menor grado de formalización que las fórmulas tradicionales, así como la capacidad para gestionar información y conocimiento, particularmente procedentes del entorno, lo que viene ligado al uso de las nuevas tecnologías de la información y comunicación que propician la virtualidad necesaria.

\section{Una Administración innovadora.}

La innovación actualmente es entendida, no solo como innovación tecnológica, sino también como la actitud de las personas que se irradia a la organización. Como se ha puesto de manifiesto los cambios sociales, culturales y económicos inciden de forma determinante en los planteamientos de la Administración pública, y como tales, exigen modificaciones estructurales y modificaciones en las prácticas, de las que no pueden aislarse los propios procedimientos, de liderazgo de equipos, de desarrollo normativo, de planificación, de gestión de conocimiento o de gobernanza. Como puso de relieve un Informe del Cabinet Office Británico (2005): «la eficacia del gobierno y de los servicios públicos depende del éxito de la innovación para desarrollar mejores modos de responder a las necesidades, de resolver los problemas y de usar bien los recursos y las tecnologías. La innovación se considera a veces un lujo prescindible o una carga adicional. Debe ser considerado como una actividad básica».

Ahora bien, la innovación en las Administraciones públicas puede hacerse desde diversas perspectivas. Por un lado, porque esa innovación puede hacerse en diferentes direcciones: fomentando la innovación en el interior de la organización, o hacia el exterior, en la relación con su entorno. Por otro lado, porque parece claro que esa innovación no es exactamente igual a la que se hace en el sector privado. En el sector público 
deberemos necesariamente innovar en el diseño de las políticas, en los servicios que prestamos, en la gestión de las personas, en los procesos, en las formas organizativas, etc. ${ }^{16}$.

Ahora bien, los innovadores del sector público no innovan en un vacío, sino en un ambiente organizativo estructurado. Algunos factores organizacionales pueden ayudar a impulsar la innovación mientras que otros pueden ir en su contra o entorpecerla ${ }^{17}$. Pedir a los empleados públicos que innoven puede no producir resultados si el ambiente organizacional en sí no apoya a la innovación.

\section{Una administración que gestiona el conocimiento.}

La gestión del conocimiento abarca al conjunto de actividades realizadas con el fin de utilizar, compartir y desarrollar el conocimiento de una organización y de los individuos que en ella trabajan, encaminándolos a la mejor consecución de sus objetivos.

La gestión del conocimiento genera recursos para las organizaciones, el denominado capital intelectual, como elemento intangible y perdurable para una gestión eficiente y sostenible en el tiempo. Mediante la gestión del conocimiento las organizaciones favorecen que el individuo se desarrolle en su trabajo aportando ideas, y al mismo tiempo se evita la fuga de conocimiento cuando las personas abandonan la organización.

Por tanto, gestionar el conocimiento significa reconocer y gobernar todas aquellas actividades y elementos de apoyo que resultan esenciales para poder atribuir a la organización y a sus integrantes la capacidad de aprender y que, al actuar como facilitadores, afectan al funcionamiento eficiente de los sistemas de aprendizaje y, por ende, al valor de la organización en el mercado ${ }^{18}$. La gestión del conocimiento dentro de una organización depende, como han puesto de manifiesto García Holgado y García-Peñalvo (2014), de un gran número de factores tanto internos (perfil de los empleados flujos de trabajo, etc.) como externos (contexto cultural, mercado, etc.), que influyen directamente en el ecosistema tecnológico que sustenta dicha gestión de tal forma que cada ecosistema es único.

Algunas Administraciones, como ha puesto de relieve Gorriti (2017), presentan el riesgo de descapitalizarse como consecuencia de las crecientes jubilaciones que se producirán en los próximos años lo que sería determinante para una intervención decisiva en este aspecto que, a su vez y visto desde otro punto de vista, puede ser una ventana de oportunidad para la reforma del empleo público sin innecesarios traumas.

\section{LOS CAMBIOS NECESARIOS EN EL SISTEMA DE EMPLEO PÚBLICO PARA AFRONTAR ESTOS RETOS}

La pregunta ineludible, a la vista de los desafíos que deberemos de enfrentar, es si disponemos de un sistema de empleo público capaz de enfrentar con solvencia estas transformaciones que habremos de acometer (sí o sí) y si finalmente será preciso modificar el marco normativo que preside éste.

16 En opinión de la OCDE (Observatory of Public Sector Innovation website, disponible en: www.oecd.org/governance/observatory-public-sector-innovation/home), los elementos temáticos que agrupan atributos organizacionales que influyen en la innovación del sector público son los siguientes:

- Personas: La dimensión cultural -cómo las personas son motivadas dentro del escenario organizacional para explorar nuevas ideas y experimentar con nuevos enfoques-. Aquí también se sugiere que el liderazgo y la manera en que las personas son seleccionadas, recompensadas, socializadas y gestionadas tendrán un impacto en la capacidad innovadora de una organización.

- Conocimiento: El rubro de conocimiento y aprendizaje que nos ayuda a considerar asuntos relacionados con recolectar, analizar y compartir información, con el desarrollo de conocimiento y con el aprendizaje. La hipótesis es que los datos, la información, el conocimiento y el aprendizaje son esenciales para la innovación y la manera en que son manejados puede apoyar o dificultar la innovación. El desafío es construir la capacidad para reunir el conocimiento disponible para mejorar las decisiones públicas sobre las soluciones innovadoras y compartir el conocimiento para impulsar la innovación social.

- Formas de trabajo: La forma en que el trabajo está estructurado dentro y entre las organizaciones puede tener un impacto en la innovación del sector público. Esto incluye el desarrollo de espacios físicos y métodos innovadores para estructurar los equipos, dividir los silos y trabajar en asociaciones entre las organizaciones y hasta entre sectores.

- Reglas y procesos: Las reglas y procesos (incluyendo el marco legal/ regulatorio, la presupuestación y la aprobación de procesos) puede ofrecer (o bloquear) oportunidades para innovar.

17 EUROPEAN COMMISSION (2013): Powering European Public Sector Innovation: Towards a New Architecture, Report of the Expert Group on Public Sector Innovation, Brussels: Directorate General for Research and Innovation, Innovation Union. URL: https:// ec.europa.eu/futurium/en/system/files/ged/42-public_sector_innovation__towards_a_new_architecture.pdf.

18 Las formas más frecuentes de transferencia de conocimiento organizacional son: foros especializados; cursos interactivos; redes de conocimiento, etc. que, con ayuda de la tecnología, buscan proporcionar las herramientas necesarias para dar soporte a los procesos y facilitar el acceso y reutilización del conocimiento. Ya existen ejemplos notables, en esta materia, como resulta ser el caso del INAP. 
La respuesta a esta cuestión debiera pasar desde luego, en primer lugar y antes de adentrarnos fervorosamente y sin suficientes criterios por el iter legislativo, en realizar necesariamente un análisis más exhaustivo y compartido de los problemas que aquejan al empleo público en el momento actual y qué modificaciones sería preciso introducir para enfrentar con éxito esta transformación que está en marcha. Es decir, y en lo que se refiere al empleo público, en qué medida, cómo y en qué aspectos la existencia de una legislación, en el doble plano estatal y autonómico, puede ayudar a resolver éstos. Desde luego, y en la actualidad, no puede argumentarse que no se es consciente de qué falla y qué no ha resultado efectivamente resuelto tras el último ciclo de reformas en esta materia. En realidad, solo queda, y no es poco, el reto de abordar este objetivo con serenidad, reflexión y la suficiente visión de futuro. Propuestas e ideas no parecen faltar (Jimenez Asensio, 2019a) ${ }^{19}$, llamadas a su urgente implementación empiezan a ser unánimes ${ }^{20}$, luego seguramente la única explicación para no enfrentar estos problemas se debe en gran medida a tres factores suficientemente conocidos derivados de la economía política de un hipotético ciclo de reformas que no deberían perderse de vista ya que a la postre serán determi-

19 Entre otros puede verse en general el blog «La mirada institucional» en la labor, que estimo que sinceramente puede calificarse de acertada, meritoria e incansable, de Rafael Jiménez Asensio.

20 El equipo de ESADEgov. (LOSADA, C.; ALBAREDA, A. (codir.); LONGO, F.; FÉREZ, M. (2017): El empleo público en España: desafíos para un Estado Democrático Eficaz. Madrid: Instituto de Estudios Económicos) ha realizado una serie de propuestas que coinciden con algunos de los planteamientos que se realizarán aquí. Entre otras señalan:

- Ligar la planificación de dotaciones y personas con la definición y reformas de políticas y programas públicos.

- Diseñar puestos de trabajo que alcancen el equilibrio adecuado entre dos tendencias actuales de signo opuesto: la especialización, exigida por las demandas de tecnificación y cualificación de las tareas, y la polivalencia, demandada por la necesidad de adaptarse a los cambios. Es del todo necesario un espacio de discrecionalidad del ocupante del puesto y de su superior jerárquico que haga posible la necesaria y constante modificación del contenido de los puestos.

- Instaurar modelos de selección que permitan articular la rapidez de la incorporación de nuevo personal y el ajuste puestopersona con el respeto a los principios de mérito, capacidad, igualdad y transparencia.

- Apostar decididamente por la mejora y profesionalización de órganos técnicos especializados e independientes para la selección, evaluación y control.

- Diseñar un contenido y unas prácticas específicas en el ámbito de la socialización del empleo público que nazcan del acuerdo parlamentario.

- Dotar de instrumentos adecuados al empleado público para abordar los temas éticos, especialmente los dilemas que se puedan presentar.

- Intensificar la diferencia entre el sistema de concurso general, que es apto en procesos de provisión de puestos relativamente parecidos y sometidos a un ciclo definido (concurso de traslado en cuerpos docentes), y los procesos «ad hoc», puesto a puesto. Parece necesario que estos últimos procesos se amplíen y generalicen incluso en puestos base que por su especialización no puedan estar sometidos a un «tratamiento genérico». Se requiere una tramitación extraordinariamente rápida: entre 2 y 4 semanas debería ser posible resolver un proceso de provisión de puestos.

- Regular y convertir en normal el acceso al empleo público de expertos sobre materias específicas ya en una fase avanzada de su carrera profesional.

- Favorecer la estabilidad de las personas en esos puestos: la tecnificación del contenido de los puestos y su complejidad abogan por una estabilidad mínima.

- Favorecer los mecanismos de flexibilidad: ágil gestión de las modificaciones de las RPT; diversificación de los horarios de trabajo para adecuarlos a diferentes entornos del servicio público; uso del trabajo a distancia en los supuestos que sea posible, etc.

- Abordar, como un fenómeno más normal de lo que hoy lo es, la terminación del vínculo con la administración por motivos disciplinarios, de evaluaciones continuas de signo negativo, por causas objetivas etc.

- Aumentar la protección de aquellas personas que ocupan puestos de trabajo reservados a funcionarios que ejercen la «auctoritas» y que son la garantía del ejercicio de la política dentro del marco legal y un factor clave para evitar la corrupción (abogados del estado, secretarios de ayuntamiento, interventores, etc.).

- Poner en marcha la evaluación del rendimiento con el fin de estimular las competencias y la motivación de los empleados públicos, mejorando así su eficacia, y medir el rendimiento de los trabajadores, lo cual facilitaría la aplicación de medidas administrativas vinculadas a la evaluación.

- Poner en marcha de la carrera horizontal con la que se permite al empleado público progresar de grado, categoría, escalón o similar sin necesidad de cambiar de puesto de trabajo. Esto permite retener especialistas técnicos competentes, favoreciendo así la tecnificación del empleo público. No obstante, la correcta aplicación de esta herramienta depende del desarrollo de capacidades de evaluación.

- Reformar el sistema retributivo del sector público, vinculándolo más a la economía real y, en especial, al sector privado, pero manteniendo las características propias que se fundamentan en las diferencias estructurales. Considerar la conveniencia de: ampliar significativamente el abanico salarial; retribuciones más ajustadas al mercado en los puestos base y ampliar la posibilidad de progresión sobre todo en los niveles superiores; mantener un nivel de competitividad salarial más ajustado a la media del mercado laboral general; introducir más componentes variables ligados a resultados y comportamientos requeridos; crear incentivos grupales; aumentar la percepción de equidad interna.

Puede consultarse, asimismo, la entrada de Jesús Fernández-Villaverde "Una «Gran Estrategia» para España (II): Las Élites Públicas" que expone distintas líneas de reflexión y que puede consultarse en https://blogs.elconfidencial.com/economia/la-manovisible/2020-10-03/espana-reforma-estrategia-elites-publicas_2773400/. 
nantes para alcanzar los objetivos que se persigan. A saber: la ausencia de una voluntad política compartida por los principales partidos políticos necesaria para enfrentar esta imprescindible agenda de reforma ya que no se aprecia en la agenda política establecida, más allá de los programas de los distintos partidos políticos, ninguna prioridad, mucho menos compartida, en este crucial aspecto más allá de modificaciones puntuales (teletrabajo, PGE 2021, etc.) o de las que se derivan de asuntos coyunturales como la recepción y necesaria implementación de los fondos europeos next generatión ${ }^{21}$; en segundo término, la visión de una acomodada «clase» sindical que ha hecho del empleo público su última trinchera y que no analiza los problemas que aquejan a éste con una visión que vaya más allá de una visión garantista -más garantista del funcionario, o de algunos funcionarios, que del ciudadano a quien ésta sirve se entiende-, necesaria pero a todas luces insuficiente, de la institución; y, por último, las resistencias no menores de las élites, cuerpos y clases funcionariales (y no funcionariales) que viven cómodamente instalados en una zona de confort completamente alejada de los contextos que la rodean y que no facilitarán, a buen seguro, ningún intento de modificación del statu quo. Complejo panorama si además se atiende a los escasos réditos electorales que, a corto plazo, puede suponer acometer una reforma del empleo público en profundidad.

Nosotros, y sin perjuicio de lo anterior que deberá ser prioritariamente enfrentado si se pretende de verdad un reset de un país atascado en un modelo burocrático-tradicional incapaz de dar respuesta a los requerimientos que se han puesto de manifiesto, daremos cuenta de algunos elementos que desde nuestro punto de vista pueden ser claves en la mejora del empleo público y que podrían justificar la necesidad de un nuevo marco normativo (estatal y autonómico) habilitante de los mismos.

A mi juicio, junto con el propio sistema de gobernanza del empleo público que debiéramos considerar pero al que ahora no nos referiremos, los principales ejes de una eventual reforma deberían pivotar sobre seis aspectos, a saber: la organización del empleo público; el sistema de selección; el sistema de recompensas e incentivos; la integridad y la transparencia; la negociación de las condiciones de trabajo y la resolución de conflictos; y, por último, la profesionalización de la gestión de recursos humanos ${ }^{22}$.

\subsection{La organización del empleo público}

En relación a la organización del empleo público tres áreas de mejora, a su vez, son fundamentales. La primera, relativa al régimen jurídico de la relación orgánica y de servicios de los empleados públicos con la Administración. Flexibilización, que no precarización, del régimen funcionarial (la superación de un proceso selectivo no debiera ser título suficiente para disfrutar de un empleo de por vida con independencia del efectivo rendimiento y la excelencia en el desempeño de las funciones) y la reducción de su generalizada e indebida extensión, pero también flexibilización en relación a la cobertura de empleos temporales dedicados a proyectos y misiones temporales sin su necesaria conversión en empleo estructural. Y adicionalmente una regulación más detallada del personal interino tras las resoluciones jurisdiccionales de los últimos años en Europa (supuestos de nombramiento, régimen jurídico y consecuencias de su desvinculación) y del personal eventual más acorde con las patologías que se llevan poniendo de manifiesto desde hace años en su desviada utilización.

La segunda, referida a la estructuración y ordenación del empleo público: instrumentos de planificación y racionalización de los cuerpos y escalas de funcionarios existentes atendiendo a las agrupaciones de puestos (Gorriti, 2011 y Cantero, 2017) ${ }^{23}$. Instrumentos como la oferta de empleo público o las relaciones de

21 La prueba del «algodón» se ha visto recientemente, a propósito de la ejecución de fondos europeos next generation, en que se han previsto distintas medidas de flexibilización de la gestión de los recursos humanos, con una perspectiva alternativa a la actual, tendentes a posibilitar la implementación de las mismas (creación de unidades temporales, puestos de trabajo provisionales, flexibilización de la movilidad y de la redistribución de efectivos, previsión de incentivos y evaluación del desempeño, etc.) y que ha puesto de manifiesto la incapacidad del sistema, sin introducir reformas en el mismo, para hacer frente a dicha ejecución.

22 Junto a ello, nuevas exigencias derivadas de la decidida incorporación de la mujer española al mundo del trabajo, y al sector público en particular, y las nuevas exigencias que la prestación de servicios requiere, imponen, asimismo, la implementación de nuevos desarrollos normativos que se plasmen en medidas tales como la profundización en la conciliación de la vida familiar y laboral; el establecimiento de medidas de discriminación positiva en la carrera administrativa a favor de la mujer en aquellos sectores de nuestra Administración en que las mismas no hayan alcanzado un mínimo de puestos de responsabilidad; nuevas formas de prestación de trabajo y descentralización de la prestación del mismo; la participación en la definición de objetivos de unidades orgánicas; un adecuado desarrollo de las situaciones administrativas que responda a los requerimientos de reestructuración de plantillas que, a buen seguro, hemos de abordar en los tiempos actuales, abordar la regulación de la desvinculación, etc.

23 Muy expresivamente el primero indica que los cuerpos deben evolucionar hacia un nuevo contenido. «Como tal agrupación de funcionarios deben establecerse una vez que se han delimitado los diseños organizativos necesarios para cumplir el servicio público; 
puestos de trabajo, en su aplicación práctica excesivamente rígidos o dependientes del ciclo presupuestario (con los efectos perversos anudados a las tasas de reposición), son absolutamente insuficientes para atender las necesidades que hoy se plantean en el empleo público y, sin embargo, resulta un clamor constatar que carecemos en el sector público de medios precisos para identificar las necesidades de personal -los actuales se han demostrado incapaces en cualquier caso de anticipar el futuro- a medio y largo plazo, y no sólo en el aspecto cuantitativo sino sobre todo en el cualitativo. Puestos de trabajo más multifuncionales y polivalentes sin adscripción definitiva a unidades orgánicas permanentes, puestos temporales atendiendo a programas o proyectos, una reordenación del tiempo de trabajo con potenciación del trabajo a distancia, a tiempo parcial, flexible o en jornada partida; el establecimiento de jornadas complementarias en momentos punta de trabajo compensadas con días de descanso en períodos de menor intensidad laboral, y otras medidas de flexibilización de la movilidad y la distribución de efectivos se presentan como ineludibles en orden a evitar compartimentos estancos (agrupación de puestos, áreas funcionales, etc). La movilidad de los empleados públicos dentro de cada Administración y entre Administraciones debe ser ágil y sencilla a fin de enfrentar desafíos del país en su conjunto que, como durante la pandemia del COVID 19, han puesto de manifiesto la rigidez del sistema en su conjunto para atender necesidades urgentes y extraordinarias (ingreso mínimo vital, rastreadores, tramitación de ERTES, etc.).

La creación de estructuras directivas profesionales se presenta también como un punto a ser definitivamente enfrentado que no admite más demora ni excusas. Nuestro modelo de función pública, y es sabido desde hace años (Jiménez Asensio, Villoria Mendieta y Palomar Olmeda, 2009), carece en gran medida de directivos públicos. El propio modelo actual de organización y de función pública, articulado en el dualismo responsables políticos-funcionarios, no los produce. Ni la selección y provisión de puestos de trabajo se dirige a ello, ni existen los mecanismos necesarios que la hagan viable: evaluación, formación, definición de funciones y garantía de las mismas, etc. Y, sin embargo, los requerimientos exigidos a nuestras Administraciones públicas demandan, cada vez con mayor insistencia fruto de la expansión en la prestación de servicios públicos que ha acontecido en los últimos tiempos, la articulación de una función directiva, que sobre todo en aquellos sectores donde se demandan resultados en términos de prestaciones a los ciudadanos, asuma actitudes más gerenciales, por supuesto dentro del aseguramiento de los bienes públicos y la especificidad que requiere este sector, y con ello un mejor servicio a los destinatarios de los servicios prestados con un paralelismo de racionalización y responsabilidad en la gestión.

\subsection{El sistema de reclutamiento y selección}

En cuanto al sistema de reclutamiento y selección también ha de ser objeto de consideración ${ }^{24}$. De muy especial consideración hemos de decir como han puesto de relieve algunos autores (Jiménez Asensio, 2018). Los procedimientos selectivos son costosos, de discutible validez y finalidad, caducos para atender las necesidades actuales, carentes de atractivo para amplias capas de profesionales que nos serán necesarios para atender los retos a los que nos enfrentamos (innovación y tecnología) y, por si fuera poco, lentos (desde que una unidad organizativa decide cubrir una vacante hasta que el funcionario efectivamente se incorpora pueden transcurrir varios años). En primer termino es necesario, y urgente, profesionalizar la selección mediante Agencias u otros sistemas que doten a los órganos de selección de autonomía funcional (Férez, 2018) ${ }^{25}$ y garantizar la imparcialidad y la transparencia en esta tarea que hoy, sobre todo en las entidades locales, distan mucho de quedar aseguradas. En segundo lugar, el sistema selectivo ha de avalar, que no lo hace plenamente en la actualidad, su adecuación a las funciones que han de ser efectivamente

deben ser el correlato lógico y posterior de decisiones organizativas y del estudio de aptitudes, conocimientos y destrezas necesarias para poder cumplir con los comportamientos laborales relevantes que satisfacen las responsabilidades asumidas por el servicio público. Sin haber organizado lo que hay que hacer, cómo debe hacerse y qué se debe saber y tener para poder hacerlo, no pueden decidirse los cuerpos».

24 Junto a otros trabajos, entre los que destacan en su integridad el número 2/2018 de la Revista Vasca de Gestión de Personas y Organizaciones, resulta de ineludible lectura y reflexión en este punto JIMÉNEZ ASENSIO, R. (2019c): "Doce tesis y seis hipótesis sobre la selección de empleados públicos y su futuro", en Jornadas sobre los procesos selectivos en la Administración Pública en la Unión Europea, nuevos planteamientos para nuevos tiempos. URL: https://rafaeljimenezasensio.files.wordpress.com/2019/04/docetesis-y-seis-hipocc81tesis-sobre-la-selecciocc81n-de-empleados-pucc81blicos-y-su-futuro-3.pdf.

25 Ejemplo, además, tenemos en países de nuestro entorno. Así, a título de ejemplo, en Irlanda la Comisión para el nombramiento de cargos públicos (https://www.cpsa.ie/) o en Portugal el Comité de contratación y selección para la Administración Pública (https:// www.cresap.pt/), pero también hay otros como Canadá o la propia Unión Europea. 
desarrolladas con posterioridad. La valoración de otros elementos distintos a las pruebas de conocimientos (que no es preciso erradicar pero si reenfocar), con mayor validez empírica y predictiva, resulta insoslayable. Las competencias, las aptitudes personales y las habilidades sociales deben encontrar asimismo un cauce dentro de los sistemas generales de acceso (oposición y concurso-oposición) ya que el éxito de la organización va a depender en buena medida de éstos. De otro lado, y en tercer lugar, es preciso concebir el proceso selectivo como un proceso que no finaliza con la realización de unas pruebas selectivas (procedimiento selectivo), sino que éstas, con las necesarias modificaciones que nos permitan mejorar su fiabilidad y su capacidad de predicción, se continúan con un proceso posterior de adecuación de la persona con la organización concreta y las funciones y tareas a desempeñar y en el que la relación jurídica debe quedar condicionada, en cuanto a su mantenimiento, al éxito en dicha adecuación. La posibilidad de que no se seleccionen únicamente el número de candidatos que se adecua al número de plazas ofertadas, el establecimiento de períodos de prueba, la introducción de la mentoría y la reforma en profundidad de los cursos de acceso son elementos a valorar.

Similares consideraciones deberían de realizarse para el sistema de provisión de puestos de trabajo, ineficiente y mal gestionado (la provisión extraordinaria sigue siendo, en realidad, la forma ordinaria de provisión), que reproduce análogas fallas con el añadido de la discrecionalidad irresponsable en la libre designación.

Todo esto implica cambios de gran calado en el modelo institucional, y en el propio sistema de gobernanza del empleo público, en que venimos basando la gestión del acceso al empleo público (y la provisión de los puestos de trabajo) desde la organización del mismo, a su desarrollo y finalización y el abandono definitivo de procesos de estabilización y similares que tanto dañan a la profesionalización del empleo público y que cíclicamente se reproducen en el sistema fruto de los efectos perniciosos de la deficiente gestión de la temporalidad y la «necesidad» de articular procesos blandos de acceso al empleo público como en estos momentos de nuevo estamos comprobando (Boltaina, 2018).

\subsection{Sistema de recompensas e incentivos}

Otro apartado necesariamente a considerar es el relativo al sistema de recompensas e incentivos (en más y en menos). La reconsideración general de todo el sistema de recompensas (ya sean retributivas o de otro tipo) y del sistema de penalización de aquellas conductas que no favorecen la mejora de la gestión de los servicios ha de ser otro punto clave a considerar. El sistema retributivo, el régimen disciplinario y otros elementos atinentes al sistema de motivación de los empleados públicos han de ser necesariamente revisados. Existe algún margen en las bases establecidas por el EBEP para hacerlo y éste ha de ser aprovechado ya que la realidad actual ofrece resultados bastantes pobres en cuanto a la eficacia del mismo y seguramente exigiría su reforma y, en algunos supuestos, su reconsideración como elemento dispositivo y no preceptivo.

Vayamos a la primera cuestión (las en más). Sencillamente no existen o son muy débiles los sistemas de incentivos. Aún peor, en algunos supuestos, son decididamente arbitrarios y no contribuyen a la profesionalización de la función pública. Los mecanismos de refuerzo de la motivación no se han puesto en marcha de forma generalizada (léase la evaluación del desempeño) y los que tímidamente lo han hecho, como la carrera horizontal, ofrecen resultados muy pobres que no han resuelto algunos de los problemas para los que se concibieron (inflación organizativa) y, al fin y a la postre, no se han plasmado en la mayoría de las ocasiones, como resulta habitual en el empleo público dada su proclividad reticente a no gestionar la «diferencia» en esta y otras materias, más que en un incremento lineal y generalizado de retribuciones incapaz de premiar y diferenciar las conductas y actuaciones merecedoras de estímulo y recompensa ${ }^{26}$. Adicionalmente es necesario enfrentar el "achatamiento» retributivo en el sector público y su mayor conexión con los salarios del mercado y habría de pensarse si las cuantías retributivas de la alta función pública no desincentivan

26 Centrándonos en el actual sistema algunos puntos pueden ser apuntados: 1. Los mecanismos de provisión siguen articulando carreras administrativas de tipo burocrático que no se adecuan a numerosos sectores de actividad de nuestra sector público; 2 . La carrera administrativa tiene poca repercusión en el monto total retributivo de forma tal que, en ocasiones, se produce una doble carrera a través del complemento específico; 3. La estructuración de la misma ha favorecido la inflación organizativa no justificada lo que, a su vez, ha dificultado políticas de promoción interna más activas al compensarse por la provisión de puestos de trabajo; 4 . Todavía subsiste una cierta falta de transparencia y arbitrariedad en la provisión de puestos de trabajo; 5 . Abuso de los sistemas provisionales de provisión de los puestos de trabajo a fin de facilitar, con posterioridad, la consolidación de dichas situaciones; 6 . La promoción interna como mecanismo de promoción generalizada y de «café para todos». 
la atracción de talento. De nuevo, no el sistema en sí mismo como todo perfectible, sino en gran medida la deficiente gestión de éste es la causa de su fracaso (Castillo Blanco, 2011).

Tampoco los mecanismos de exigencia de responsabilidad -los mecanismos en menos- ofrecen resultado alguno dado, entre otras cosas (desidia y ausencia de dirección efectiva de los recursos humanos en las unidades administrativas de línea), a su estrecha vinculación al ius puniendi general del Estado que bien merecería su reconsideración (Castillo e Ildefonso, 2002). Quiere decirse que el fundamento de la potestad disciplinaria de la Administración pública ha de ser reconsiderado e inserto en un ámbito doméstico (potestad organizativa) presidido por los artículos de la Constitución española que versan sobre el funcionamiento y los principios rectores de dicha organización administrativa, esto es, los artículos 103 y $9.3 \mathrm{CE}$. Con otras palabras, rescatar el Derecho disciplinario del ámbito sancionador administrativo para insertarlo en el Derecho de la función pública. Esta nueva ubicación dogmática, sin perjuicio de que se garantizasen los derechos del empleado (que no quedarían en la práctica reducidos), disminuiría la problemática de dar respuesta a requerimientos conectados con el principio acusatorio, los principios de legalidad, non bis in ídem, tipicidad, etc. ${ }^{27}$, e introduciría mayor flexibilidad lo que, al fin y a la postre, facilitaría, lo que ahora no ocurre, su aplicación a fin de corregir conductas desviadas o no conformes con los objetivos de la organización.

$\mathrm{Y}$, en paralelo, es preciso estructurar también claramente una tabla de deberes y de exigencias éticas que materialice las previsiones en este caso recogidas en el EBEP y responda a las exigencias de servicio que el ciudadano plantea a nuestras Administraciones públicas (controles de integridad, calidad, transparencia, cartas de servicios, reestructuración de los sistemas de responsabilidad, etc.).

\subsection{El sistema de integridad y transparencia}

En este sentido, y en relación a la integridad y la transparencia, también deben realizarse distintas modificaciones. Las previsiones, en esta materia, establecidas, tanto en el EBEP como en la legislación de incompatibilidades, han de ser reorientadas.

De un lado, y en materia de transparencia (Cuenca, 2018), la legislación básica de empleo público -Ley 30/1984 (LRFP) y también el RD Legislativo 5/2015 (TREBEP)-, a diferencia de algunas normas legales de las Comunidades Autónomas en esta materia más atentas todo hay que decirlo a esta cuestión, resulta muy limitada en cuanto al acceso a la información relativa a las distintas cuestiones que una política de integridad exige ${ }^{28}$. De otro lado, la legislación de incompatibilidades, surgida en un determinado contexto histórico orientado en ese momento, principalmente, a impedir la simultánea ocupación de dos empleos públicos y materia que no resultó abordada con ocasión de las reformas impulsadas por el EBEP, resulta insuficiente para dar respuesta a los conflictos de intereses que se plantean en el desarrollo diario de la actividad administrativa. Aún así dicha reforma del marco normativo -necesaria como decimos, pero insuficiente- no tendrá los efectos que se desean con una gestión meramente normativa (traducida en prohibiciones y deberes) o procedimental de los retos que implica. Me explico.

La ética en la conducta de los empleados públicos, que ha de estar orientada al servicio público, conlleva compromisos de naturaleza personal, de calidad institucional para lograr los fines de la organización y compromisos en relación con la ciudadanía. Algunas normas hacen referencia al Buen Gobierno de forma muy reduccionista refiriéndose únicamente a medidas de control de la corrupción, que es lo que caracterizaría precisamente lo contrario, un «mal gobierno», pero bien entendido el desafío que hoy se nos presenta consiste más bien en promover un sector público profesional basado en la meritocracia, consagrado a los valores y a la buena gobernanza del servicio público, que favorezca, además, una cultura organizativa de la transparencia dentro del sector público que responda a las preocupaciones relacionadas con la integridad, sin perjuicio de implementar un marco de control y gestión de riesgos que salvaguarde la integridad en las entidades del sector público.

27 Principios que, si por una parte se afirman en la dogmática e inclusive se recogen en las normas, por otro lado se flexibilizan («matizan» o «modulan» en la expresión usada por los tribunales) en su aplicación practica hasta tal punto que, en ocasiones, difícilmente son reconocibles o tienen alguna validez efectiva más allá de su mera invocación nominal. Un ejemplo reciente de dicha aplicación tan solo formal lo tenemos con el principio acusatorio en la reciente STS de 22 de octubre de 2020 (rec. 4535/2019).

28 Véase, a título de ejemplo, la STS de 15 de octubre de 2020 (rec.3846/2019) que aborda la transparencia y publicidad tanto de los objetivos perseguidos por un ente público y su grado de cumplimiento como de los criterios de distribución de los fondos públicos, en este caso relacionados con el reparto de la retribución por productividad entre los empleados públicos. 
La ética institucional, a diferencia del Derecho, pretende construirse en sentido «positivo», con un fuerte carácter preventivo y permear las conductas y comportamientos (esto es, los «hábitos» o el carácter) de los servidores públicos, mediante procesos de «internalización» de tales valores y normas de conducta.

En el campo de la ética institucional de carácter público, la pertenencia de un servidor público a una determinada institución le obliga no solo a cumplir con las normas jurídicas del propio ordenamiento, sino también a adecuar sus conductas o comportamientos a un conjunto de valores y principios que son de necesario cumplimiento dada la posición que ocupa, las funciones que desarrolla y la imagen institucional que traslada esa persona en la estructura de cada entidad pública y sobre la propia ciudadanía.

En todo caso, construir correctamente un sistema de gobernanza ética, encuadrado en una Buena Gobernanza o Buen Gobierno, requiere una serie de pasos que son importantes. A saber: disponer de una política de integridad; construir un modelo institucional de gobernanza ética; definir un marco de gestión ética; y, por último, la generación de un clima ético que conlleve un profundo y gradual cambio cultural en las organizaciones públicas ${ }^{29}$.

\subsection{El sistema de relaciones laborales}

En relación al sistema de negociación de las condiciones de trabajo y de resolución de conflictos cualquier reforma normativa que haya de emprenderse ha de considerar de especial interés este aspecto en ocasiones lastrado por un indisimulado condicionamiento político que unido, en más de una ocasión, a una ausencia de capacidad técnica de la representación publica producen un efector distorsionador del sistema de empleo público. Un conjunto de aspectos han de ser valorados y de nuevo repensados a la vista del resultado de las reformas realizadas a partir de 2007 ( $y$ en el que la legislación de las Comunidades Autónomas prácticamente desaparecida en este punto apenas ha incidido reiterando en su mayoría lo ya dispuesto en el texto básico ${ }^{30}$. Creo que tres campos, en este concreto aspecto, debieran ser objeto de acción del legislador.

El primero, relativo al marco institucional en que se desenvuelve ésta: a saber: la estructura de la negociación, el propio procedimiento de negociación, el régimen de adopción de acuerdos, la naturaleza de los acuerdos adoptados en una mesa de negociación, las consecuencias derivadas de la no obtención de un acuerdo, los efectos de su aprobación por el correspondiente órgano de gobierno y de su falta de aprobación han de ser reconsiderados dados los vacíos y fallas que se presentan en su aplicación práctica.

El segundo referido a las materias negociables, y en especial, las materias comunes entre personal laboral y funcionario y las materias excluidas de ésta y, más en concreto, las referidas a las potestades de organización y todo lo relativo a la garantía del principio de mérito que requieren de una aclaración (y sino véase a título de ejemplo lo que está aconteciendo con los procesos de estabilización de personal empren-

29 Siguiendo el esquema de la OCDE cabe resumir que un «Marco de Integridad Institucional» que pretenda articular una «infraestructura ética» debería incorporar, al menos, los siguientes elementos:

A) Un Código Ético o de Conducta, también denominado en ocasiones como Código Ético y de Buen Gobierno. Este Código debe recoger los Valores y las Normas de Conducta anudadas a tales valores. También puede incluir Principios de Buen Gobierno y Normas de actuación, pero esto tiene un componente más adjetivo y distante, por lo común, de los Marcos de Integridad Institucional, salvo que se conecten con la Eficiencia, la Transparencia y la Rendición de Cuentas.

B) Los Códigos por si solos no incorporan otra cosa que «letra» y pueden derivar en Códigos declarativos; es por ello muy importante que incorporen Mecanismos de Difusión, Prevención y Desarrollo de la Cultura Ética en las organizaciones, dada su finalidad preventiva y la necesidad objetiva de que se «internalicen» o «interioricen».

C) Un Marco de Integridad Institucional que promueva la infraestructura ética debe disponer, asimismo, de procedimientos, canales, circuitos, para garantizar la efectividad del Código Ético o de Conducta. A través de ellos se plantea la resolución de dilemas éticos por parte de los servidores públicos, quejas o, inclusive, denuncias.

D) El Código debe garantizar asimismo su efectividad por medio de la articulación de un Sistema de Garantía, que habitualmente es una Comisión de Ética (órgano colegiado) o de un Comisionado de Ética (órgano unipersonal), encargado, entre otras cosas, de resolver tales dilemas éticos, orientar en caso de consultas, dirimir conflictos éticos y resolver las quejas o reclamaciones que se puedan suscitar.

E) Y, por último, el Marco de Integridad se debe cerrar con un Sistema de Seguimiento y Evaluación de la aplicabilidad del Código y del funcionamiento del Marco en su conjunto. Lo habitual en el mundo anglosajón es que los Códigos se configuren como «instrumentos vivos», que se van actualizando a través de modificaciones o adaptaciones permanentes al nuevo contexto y a las exigencias o estándares del momento, pero también por medio de Guías Aplicativas, que protocolizan como complemento a los Códigos las respuestas a los dilemas éticos y las resoluciones adoptadas por la Comisión o el Comisionado en lo que afecta a quejas y denuncias.

30 Siguen prácticamente vigentes plenamente la mayoría de los problemas que ya apunto la Comisión constituida en su día para la elaboración del EBEP. Puede consultarse, en este punto, Informe de la comisión para el estudio y preparación del estatuto básico del empleado público (2005): Madrid: Instituto Nacional de Administración Pública, págs. 166-201. 
didos y la negociación del propio contenido de las pruebas). Por supuesto, siguen siendo de plena vigencia los problemas en su día detectados en el empleo público local en este punto y en el que los mecanismos en su día diseñados (adhesión y negociación supramunicipal) no han ofrecido los resultados esperados quizás por la indefinición de los mismos.

Un tercer aspecto a destacar es la necesidad de mejorar los medios extrajudiciales de solución de los conflictos. A nadie se le oculta la alta conflictividad, tanto en las relaciones laborales como funcionariales, que padecen nuestras Administraciones públicas y que alcanza, en un correlato lógico, a los órganos jurisdiccionales ya sean las Salas de los Tribunales Superiores de Justicia o los Juzgados de lo ContenciosoAdministrativo. Sin embargo, dicho estado de cosas no es satisfactorio ni para los empleados públicos que aprecian que abusos manifiestos no tienen una solución pronta y satisfactoria, ni para los tribunales que se ven abocados a resolver imperativamente conflictos que podrían tener otras vías de solución, pero ni, inclusive, para las propias organizaciones públicas cuya actuación en este concreto aspecto no potencia la motivación de los empleados públicos y, en ocasiones, ofrecen una sensación de abuso injustificable en la toma de decisiones, articulada de forma unilateral en una gran parte de los supuestos, que no favorece la armonía en las relaciones laborales.

Para la mayoría de estos problemas se han apuntado soluciones y existen propuestas sensatas (Mauri, 2011 y 2019) que, sin lugar a dudas, mejorarían los problemas apuntados y solo queda preguntarse cuáles son las razones para vivir con comodidad en este confuso escenario que hace saltar por los aires cualquier intento de racionalización y homogeneización de las condiciones de trabajo.

\subsection{La profesionalización de la gestión del empleo público}

Queda, por último, realizar, aunque se sea breve, una reflexión sobre la profesionalización de la gestión de recursos humanos que parece que, en otros campos, como la compra pública si ha encontrado el debido respaldo en la propia normativa europea. Reiteradamente se ha puesto de manifiesto que, aún con mejoras normativas como se ha ido desarrollando en este epígrafe, las fallas y los problemas de las que actualmente está aquejado nuestro empleo público se encuentran en mayor medida en otros aspectos condicionantes del estado actual. Sin duda, una de ellas está en el condicionamiento político, que no técnico, que preside la materia; otro en el espejismo de una anhelada paz social que tuerce y empaña la consecución de objetivos ciertos en esta materia; pero otra, y no menor, está en el amateurismo existente en esta materia que es determinante de que la gestión de personal no llegue, cuando lo hace, sino a administrar procedimientos básicos relativos al desenvolvimiento de la relación orgánica y de servicio de los empleados públicos que se traducen en procedimientos y no en procesos que añadan valor a la organización. Unos y otros son necesarios, pero estos últimos son imprescindibles si queremos introducir cambios efectivos en el modelo de empleo público.

El escaso valor que se asigna a las unidades de recursos humanos ausentes de una profesionalización necesaria para la gestión de procesos complejos, multidisciplinares (la gestión del talento no es una cosa relativa tan solo al régimen jurídico) y en los que la norma solo es un punto de partida para abordar la realización de los mismos está en la base, también, de la deficiente y desviada gestión de los sistemas de gestión de los recursos humanos. Ya nos refiramos a los procesos de selección, a los sistemas de incentivos o, por referirnos a un último aspecto, a los procesos de negociación de las condiciones de trabajo en la mayoría de los casos siempre encontraremos una ausencia de capacidad a la que es preciso poner urgente remedio. Formación, incorporación de talento multidisciplinar y especializado y valorización de sus cometidos son imprescindibles en este aspecto. En esta materia, y en concreto en las entidades locales, es preciso encontrar fórmulas supramunicipales y cooperación para hacer frente a dicho problema.

\section{A MODO DE CONCLUSIÓN: CAMBIAR LA CULTURA PARA CAMBIAR EL SISTEMA}

En efecto, como ya se anticipó no parece sensato fiar tan solo a una reforma legal la solución a los problemas apuntados. El éxito de las eventuales reformas que eventualmente se emprendieran tienen una clara dependencia, en gran medida, de los factores que permiten un verdadero cambio institucional. Las reformas legales serán un primer paso, pero lo verdaderamente relevante será el rigor con que se apliquen éstas y el cambio de cultura administrativa que exigen para su éxito. Y eso será, con todas las reformas legales que se quieran, sin duda, el punto de equilibrio para el éxito de los cambios que nuestro empleo público demanda. Distintos autores ya pusieron de relieve la necesidad urgente, para que las reformas del Estado alcancen el 
éxito que se espera de las mismas, de que se produzca un cambio institucional (Prats, 1997 y 2000). Quiere decir ello, en palabras de dicho autor, que «las organizaciones estatales no son libremente disponibles; contrariamente, se encuentran ampliamente sobredeterminadas por el tipo de institucionalidad pública existente, es decir, por las normas y reglas -formales e informales- que establecen los fines, límites, actores, procedimientos y formas de participación en la acción colectiva, así como por los correspondientes modelos mentales, actitudinales y valorativos que prestan legitimidad, permiten la vigencia y dificultan el cambio de tales reglas y normas». No hemos tomado debidamente nota de ello.

De todo lo cual deduce el autor citado una conclusión que bien puede resultarnos aplicable a nuestro caso: «si la institucionalidad pública es el marco de incentivos de las organizaciones públicas, cualquier reforma de éstas sólo será positiva y duradera en la medida en que contribuya a reformar también positiva y duraderamente el fondo o marco institucional en que la organización se inserta» y, correlato de lo anterior, que si reconocemos como cierto lo expuesto la reforma del sistema de empleo público no puede ser solamente una operación meramente técnica sometiéndola a una lógica de cambio perfectamente planificado, sino que va a requerir también de un proceso constante, dilatado a lo largo del tiempo, que modifique también aquellos elementos subyacentes que en forma inercial permanecen en el empleo público sea cual sea la norma legal o reglamentaria que se dicte.

$Y$ es que el planteamiento realizado hasta aquí no obvia que, junto a los elementos formales normativos, hay un conjunto de reglas informales que matizan y condicionan la interpretación de la normativa existente, o de la que eventualmente pueda dictarse, y que son determinantes para que las soluciones propuestas y su implementación sigan una inercia que no cambia, en lo esencial, nada relevante. (Losada, Albareda, Longo y Férez, 2017) ${ }^{31}$.

La reforma del empleo público exige por ello un gran acuerdo institucional para llevarla a cabo y concebirla, más que como una reforma legal, como un proceso continuado y persistente a lo largo del tiempo que exige leer adecuadamente la economía política de ese cambio. Las experiencias hasta ahora acontecidas en nuestro país creo que ponen en evidencia dicho aspecto en mayor medida que cualquier argumento que pudiera ofrecerse aquí.

\section{REFERENCIAS BIBLIOGRÁFICAS}

BALAGUER CALLEJÓN, F. (2006): "Las cuestiones competenciales en los actuales procesos de reforma de los Estatutos de Automonía”, en Revista General de Derecho Constitucional (RGDC), núm. 1.

BOLTAINA BOSCH, X. (2018): "Los procesos selectivos «blandos» y sus efectos sobre la profesionalización del empleo público", en Revista Vasca de Gestión de Personas y Organizaciones Públicas, Procesos selectivos, número especial 2, págs. 140-155.

BRESSER-PEREIRA, L. C. (2001): "Ciudadanía y res pública: la aparición de los derechos republicanos", en Revista Instituciones y Desarrollo, núms. 8 y 9, págs. 7-42.

CANTERO MARTÍNEZ, J. (2016): Claves para la modernización de la estructura funcionarial. La coexistencia ordenada de cuerpos y puestos de trabajo. Madrid: Thomson Reuters-Aranzadi.

CANTERO MARTÍNEZ, J. (2017): "Hacia una concepción más técnica y moderna de los cuerpos de funcionarios: el cuerpo como correlato de las áreas funcionales", en Cuadernos de Gobierno y Administración Pública, vol. 4, núm. 1, págs. 39-57. DOI: https://doi.org/10.5209/CGAP.56024.

CATALÁ, R.; CORTEZ, O. (2020): Talento público para una Administración tras el corona schok. Propuestas para una reforma ineludible. Barcelona: EsadeGov-PwC. https://www.pwc.es/es/publicaciones/tercer-sector/talento-publicopara-administracion-corona-shock.pdf.

CASTILLO BLANCO, F. A. (2011): "El sistema salarial en la ley de empleo público de Castilla-La Mancha", en Revista jurídica de Castilla-La Mancha, núm. 50, págs. 269-318. https://docm.jccm.es/portaldocm/descargarArchivo. do? ruta=Revista50.pdf\&tipo $=$ rutaRevistas.

31 Dichos autores subrayan, entre éstas, las siguientes: la idea de igualdad, muchas veces interpretada en términos de homogeneidad, especialmente en el acceso a los puestos de trabajo, a la carrera administrativa y en el sistema salarial y de incentivos; el mérito y la capacidad como principios que regulan el acceso y el desarrollo de la carrera profesional, básicamente medidos a partir de su implementación formal; la unidad, a menudo asociada a la uniformidad en la configuración del sistema de función pública (clasificación de los empleados, reclutamiento, remuneración, estructura de puestos de trabajo); la centralización de la gestión y la administración de las principales actividades vinculadas a la gestión de recursos humanos, tanto en la relación entre Estado, comunidades autónomas y entes locales como en el seno de las respectivas administraciones; la jerarquía como principal mecanismo de coordinación entre unidades, aunque matizada por el surgimiento de regímenes singulares que favorecen un sistema más próximo a una red que a una estricta pirámide. 
DA. Nueva Época - N. ${ }^{\circ}$, enero-diciembre 2020 - ISSN: 1989-8983 - DOI: https://doi.org/10.24965/da.i7.10889 - [Págs. 8-32]

Un sistema de empleo público distópico: ¿sería preciso reformar el EBEP?

Federico Castillo Blanco

CASTILLO BLANCO, F. A.; ILDEFONSO HUERTAS, R.: (2002): "La renovación de la dogmática del derecho disciplinario: a propósito de las infracciones y sanciones en el personal estatutario de la seguridad social”, en Revista de Administración Pública. núm. 158, págs. 7-49. http://www.cepc.gob.es/publicaciones/revistas/revistasel ectronicas? IDR=1\&IDN=156\&IDA=24436.

CUENCA CERVERA, J. J. (2018): Transparencia y Función Pública. Colección: Estudios de Relaciones Laborales, núm. 12. Barcelona: CEMICAL/Diputación de Barcelona. https://cemical.diba.cat/es/publicaciones/ficheros/ CEMICAL_Transparencia_Funcion_Publica.pdf.

EUROPEAN COMISSION (2013): Powering European Public Sector Innovation: Towars A New Architecture - Report of the Expert Group on Public Sector Innovation. https://ec.europa.eu/futurium/en/system/files/ged/42-public sector_innovation_-_towards_a_new_architecture.pdf.

FÉREZ FËRNÁNDEZ, M. (2018): "La configuración institucional de las comisiones de mérito en los procesos selectivos: experiencias comparadas y aplicación al contexto español”, en Revista Vasca de Gestión de Personas y Organizaciones, núm. especial 2, págs. 126-139. https://dialnet.unirioja.es/servlet/articulo?codigo=6560625.

FUENTETAJA PASTOR, J. A. (2013): Pasado, presente y futuro de la Función Pública. Entre la politización y la patrimonialización, pág. 481. Navarra: Thomson Reuters-Civitas.

GARCÍA-HOLGADO, A.; GARCÍA-PEÑALVO, F. J. (2014): "Patrón arquitectónico para la definición de ecosistemas de eLearning basados en desarrollos open source", en RODRÍGUEZ, J. L. S.; BEARDO, J. M. D.; BURGOS, D. (eds.): Proceedings of 2014 International Symposium on Computers in Education (SIIE), págs. 137-142. Celebrado en Logroño, La Rioja, España, del 12-14 de noviembre de 2014. Logroño: Universidad Internacional de la Rioja (UNIR). https://doi.org/10.1109/SIIE.2014.7017711.

GRAELLS, J.; RAMILO, M. (2013): Ciudadanía y administraciones en red: la administración pública ante la nueva sociedad en red. Madrid: INAP; Netbiblio. https://www.inap.es/documents/10136/1703462/Pag/niciaCiudadan\%25c3\%25ada-y-administraciones-en-red.pdf/9e4e7486-b55e-69d6-15a7-15c48bf7a19d.

GORRITI BONTIGUI, M. (2011): "El sistema de selección para el acceso a una Función Pública postburocrática", en NUEVAS POLÍTICAS PÚBLICAS. Anuario multidisciplinar para la modernización de las administraciones públicas, núm. 7, págs. 147-161. URL: http://www.juntadeandalucia.es/institutodeadministracionpublica/anuario/ jsp/herramientas/verArticulo.jsp?ca=502\&anyo=N\%BA\%207\%20A\%D10\%202011\&v=2\&url=estudios7/estudio9/ estudio01.htm.

GORRITI BONTIGUI, M. (2017): "Análisis cognitivo de tareas. Gestión de conocimiento en la administración general del país vasco (AGPV)", en Revista Vasca de Gestión de Personas y Organizaciones Públicas, núm. especial 1, págs. 60-69.

HABERMAS, J. (1992): Between facts and norms. Cambridge, MA: The Mit Press. https://doi.org/10.7551/ mitpress/1564.001.0001.

INSTITUTO NACIONAL DE ADMINISTRACIÓN PÚBLICA (2005): Informe de la comisión para el estudio y preparación del estatuto básico del empleado público. Madrid: Instituto Nacional de Administración Pública (INAP).

JIMÉNEZ ASENSIO, R. (2018): "Repensar la selección de empleados públicos: momento actual y retos de futuro", en Revista Vasca de Gestión de Personas y Organizaciones, núm. especial 2, págs. 8-29.

JIMÉNEZ ASENSIO, R. (2019a): "El (inaplazable) relevo generacional en las Administraciones públicas: desafíos en un entorno de revolución tecnológica y de crisis fiscal como consecuencia de la pandemia de 2020", en Anuario de Derecho Municipal, núm. 13, págs. 85-131.

JIMÉNEZ ASENSIO, R. (2019b): "Políticas de Recursos Humanos en la Administración Local: estado de la cuestión y propuestas de cambio", en El Consultor de los Ayuntamientos y los Juzgados, núm. extra 5, págs.18-29.

JIMÉNEZ ASENSIO, R. (2019c): "Doce tesis y seis hipótesis sobre la selección de empleados públicos y su futuro", en Jornadas sobre los procesos selectivos en la Administración Pública en la Unión Europea, nuevos planteamientos para nuevos tiempos. https://rafaeljimenezasensio.files.wordpress.com/2019/04/doce-tesis-y-seis-hipocc81tesissobre-la-selecciocc81n-de-empleados-pucc81blicos-y-su-futuro-3.pdf.

JIMENEZ ASENSIO, R.; CASTILLO BLANCO, F. A. (2009): Informe sobre el Empleo Público Local. Balance y propuestas para su racionalización en el marco del empleo público. Madrid: Fundación Democracia y Gobierno Local. https://repositorio.gobiernolocal.es/xmlui/bitstream/handle/10873/583/Sumario_5_14. pdf? sequence $=1$ \&isAllowed $=y$.

JIMÉNEZ ASENSIO, R.; VILLORIA MENDIETA, M.; PALOMAR OLMEDA, A. (2009): La dirección pública profesional en España. Madrid: Marcial Pons Ediciones Jurídicas y Sociales. 1. ${ }^{a}$ ed.

LONGO, F. (1995): "Reforma del empleo público: Tótem y Tabú", en Gestión y Análisis de Políticas Públicas, núm. 2 , enero-abril, págs. 5-15. DOI: https://doi.org/10.24965/gapp.v0i2.17.

LONGO, F. (2003): "Revisió d’alguns elements clau de la situació de la funció pública a Catalunya", en FERNÁNDEZ, A.; MUÑOZ, X.; CISTERNAS, X. (coords.): Informe Pi i Sunyer sobre l'Administració de la Generalitat de Catalunya. Barcelona: Fundació Carles Pi i Sunyer.

LONGO, F. (2004): Mérito y flexibilidad: la gestión de personas en las organizaciones del sector público. Barcelona: Paidos.

LOSADA, C.; ALBAREDA, A.; LONGO, F.; FÉREZ, M. (2017): El empleo público en España: desafíos para un Estado Democrático Eficaz. Madrid: Instituto de Estudios Económicos. 
LOSADA MARRODÁN, C. (2017): "Aproximación a un diagnóstico y sugerencias de mejora del empleo público en España”, en Revista Vasca de Gestión de Personas y Organizaciones Públicas, núm. 13, págs. 8-25. https://www. ivap.euskadi.eus/z16-a3rvop/es/contenidos/informacion/copia12_revgp/es_def/index.shtml.

MARSHALL, T. H. (1950): The Crisis in Marxist Sociology. Cambridge.

MAURI MAJÓS, J. (2011): "La negociación colectiva en el desarrollo legislativo tras el Estatuto Básico del Empleado Público y, en particular, en el anteproyecto de Ley de Empleo Público de Aragón", en Revista Aragonesa de Administración Pública, núm. XIII: Monográfico: El empleo público en Aragón y tendencias de futuro, págs. 271295. https://dialnet.unirioja.es/servlet/articulo?codigo=5547441.

MAURI MAJOS, J. (2019): "El procedimiento de negociación y aprobación de los acuerdos colectivos en la función pública", en Revista Vasca de Gestión de Personas y Organizaciones Públicas, núm. 17, págs. 130-149. http:// diposit.ub.edu/dspace/bitstream/2445/162259/1/694373.pdf.

OCDE (2006): La Modernización del Estado: el camino a seguir. Madrid: INAP. https://doi.org/10.1787/9789264030305-es.

PAREJO ALFONSO, L. (1991): Crisis y renovación en el Derecho Público. Madrid: CEC.

PAREJO ALFONSO, L. (1999): "El Estado como poder y el derecho regulador de su actuación, hoy; algunas de las transformaciones en curso", en Revista del Clad Reforma y Democracia, núm. 15.

PASCUAL ESTEVE, J. M. (2011): El papel de la ciudadanía en el auge y decadencia de las ciudades: el fin del gerencialismo o la recuperación de lo público y sus actores. Valencia: Tirant lo Blanch.

PETTIT, P. (1997): Republicanism: A Theory of Freedom and Government. Oxford: Oxford University Press. $1 .^{a}$ ed.

PRATS I CATALÀ, J. (1997): "Fundamentos conceptuales para la reforma del Estado: el redescubrimiento de las instituciones", en PRATS I CATALÀ, J., La reforma de los legislativos en América Latina. Valencia: Tirant lo Blanc.

PRATS I CATALÀ, J. (2000): "Del clientelismo al mérito en el empleo público. Análisis de un cambio institucional", en BIBLIOTECA DE IDEAS del Instituto Internacional de Gobernabilidad, Universidad Oberta de Catalunya. http:// www.top.org.ar/ecgp/FullText/000000/PRATS\%20i\%20CATALA,\%20Joan\%20-\%20Del\%20clientelismo\%20al\%20 merito.pdf.

RAMIÓ MATAS, C. (2017): La Administración 2050: La Administración Pública del Futuro en la Sociedad de la Innovación y del Aprendizaje. Madrid: Editorial Tecnos.

SÁNCHEZ MORÓN, M. (2012): "La administración tras la crisis: el empleo público" en SUMAS - Congreso sobre Gestión de Recursos Humanos en la Administración Pública, págs. 1-12, Ayuntamiento de Vitoria-Gasteiz.

SEVILLA MERINO, J.; BELANDO GARÍN, B.; FABREGAT MONFORT, G.; GARCÍA CAMPÁ, S. (2017): Libro Violeta de la Función Pública Valenciana. Valencia: Gobierno de la Generalitat Valenciana. http://www.justicia. gva.es/documents/19317797/163586359/Libro+Violeta_versi\%C3\%B3n+web.pdf/845e961d-4690-40db-87ab$1 f 12 c 13 c a 538$.

SHMIDT-ASSMANN, E. (2001): "El Derecho Administrativo General desde una perspectiva europea", en Justicia Administrativa, pág. 6 y ss.

SKINNER, Q. (1978): The Foundatións of Modern Political Thought. Cambridge: Cambridge University Press.

UVALLE BERRONES, R. (2009): "Condiciones, procesos y tendencias de la administración pública contemporánea", en Convergencia. Revista de Ciencias Sociales, vol. 16, núm. 49, enero-abril, págs. 73-102. Toluca: Universidad Nacional Autónoma de México. https://convergencia.uaemex.mx/article/view/1269.

VELASCO CABALLERO, F. (2019):"Reformas de la Administración pública: fenomenología, vectores de cambio y función directiva del Derecho administrativo", Anuario de la Facultad de Derecho de la Universidad Autónoma de Madrid, núm. 23, págs. 107-143. 